San Jose State University

SJSU ScholarWorks

Master's Theses

Master's Theses and Graduate Research

1992

\title{
The Development of a statistical assessment methodology for collection management in a public library
}

Carolyn Ann King Denny

San Jose State University

Follow this and additional works at: https://scholarworks.sjsu.edu/etd_theses

\section{Recommended Citation}

Denny, Carolyn Ann King, "The Development of a statistical assessment methodology for collection management in a public library" (1992). Master's Theses. 515.

DOI: https://doi.org/10.31979/etd.7x57-m8h6

https://scholarworks.sjsu.edu/etd_theses/515

This Thesis is brought to you for free and open access by the Master's Theses and Graduate Research at SJSU ScholarWorks. It has been accepted for inclusion in Master's Theses by an authorized administrator of SJSU ScholarWorks. For more information, please contact scholarworks@sjsu.edu. 


\section{INFORVATION TO USERS}

This manuscript has been reproduced from the microfilm master. UMI films the text directly from the original or copy submitted. Thus, some thesis and dissertation copies are in typewriter face, while others may be from any type of computer printer.

The quality of this reproduction is dependent upon the quality of the copy submitted. Broken or indistinct print, colored or poor quality illustrations and photographs, print bleedthrough, substandard margins, and improper alignment can adversely affect reproduction.

In the unlikely event that the author did not send UMI a complete manuscript and there are missing pages, these will be noted. Also, if unauthorized copyright material had to be removed, a note will indicate the deletion.

Oversize materials (e.g., maps, drawings, charts) are reproduced by sectioning the original, beginning at the upper left-hand corner and continuing from left to right in equal sections with small overlaps. Each original is also photographed in one exposure and is included in reduced form at the back of the book.

Photographs included in the original manuscript have been reproduced xerographically in this copy. Higher quality $6 "$ " 9 " black and white photographic prints are available for any photographs or illustrations appearing in this copy for an additional charge. Contact UMI directly to order.

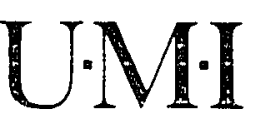

University Microfilms internationa

A Bell \& Howell Information Company

300 North Zeeb Road. Ann Arbor. MI 48106-1346 USA

313:761-4700 800:521-0600 


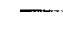


Order Number 1951208

The development of a statistical assessment methodology for collection management in a public library

Denny, Carolyn Ann King, M.A.

San Jose State University, 1992 



\title{
THE DEVELOPMENT OF A STATISTICAL ASSESSMENT METHODOLOGY FOR COLLECTION MANAGEMENT IN A PUBLIC LIBRARY
}

\author{
A Thesis \\ Presented to \\ The Faculty of the School of Library \& Information Science
}

San Jose State University

In Partial Fulfillment

of the Requirements for the Degree

Master of Arts

By

Carolyn Ann King Denny

December 1992 


\section{APPROVED FOR THE SCHOOL OF LIBRARY AND INFORMATION SCIENCE}

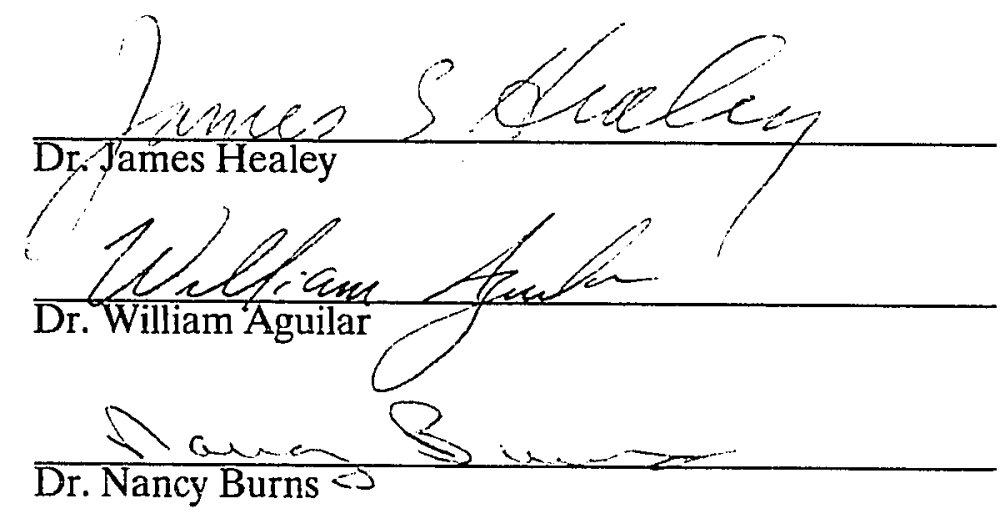

\section{APPROVED FOR THE UNIVERSITY}

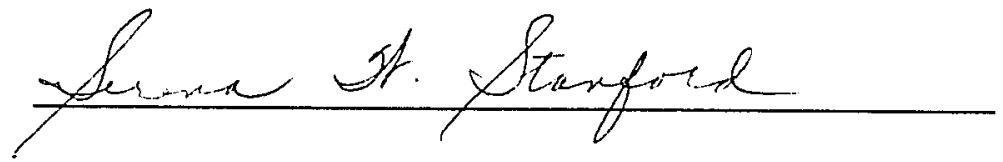




\begin{abstract}
THE DEVELOPMENT OF A STATISTICAL ASSESSMENT METHODOLOGY FOR COLLECTION MANAGEMENT IN A PUBLIC LIBRARY by Carolyn A. K. Denny

This thesis addresses the problem of developing procedures to evaluate and manage the collection of a small public library. Data from three branch libraries was used including holdings and acquisitions data, circulation records, and interlibrary loan statistics. To save time and facilitate the ease of interpreting the analysis of the data, a commonly available spreadsheet was used to make calculations and graph the results. Evaluation of the circulating non-fiction collections, utilizing the methodology developed in this study, produced a collection profile which could be used as a basis for making collection management decisions. Analysis of the results did not support the expectation that public service staff would necessarily make collection development decisions that would deviate less from usage patterns than non-public service staff.
\end{abstract}




\section{TABLE OF CONTENTS}

LIST OF ILLUSTRATIONS ...................................................................................vi

LIST OF TABLES ….......................................................................................... vii

\section{Chapter}

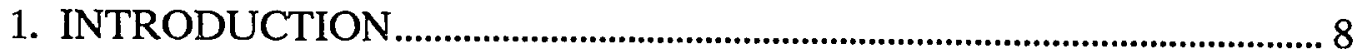

2. REVIEW OF THE LITERATURE ............................................................... 15

3. METHODOLOGY................................................................................... 24

Collection Analysis ................................................................................. 25

Selection/Acquisitions Analysis ............................................................... 27

Collection Profile ......................................................................................... 27

Collection and Acquisitions Data ............................................................. 30

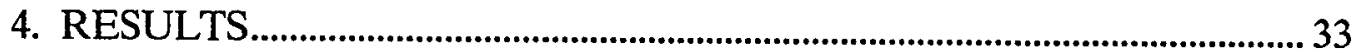

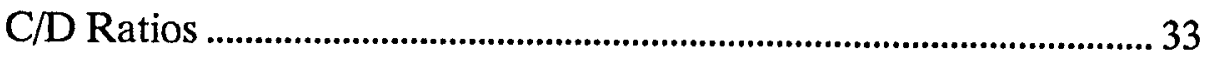

Composite Analysis of C/D Ratios........................................................... 40

ILL/Holdings Ratio ............................................................................... 41

Selection/Acquisitions Analysis ............................................................. 43

Composite Analysis of SLB and ALB................................................... 44

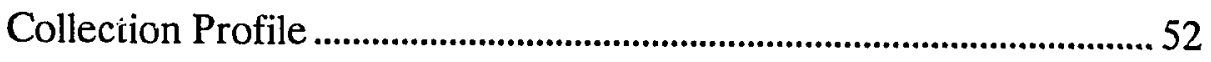

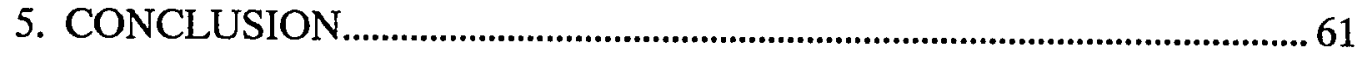

Appendix

1. DEWEY DECIMAL CLASSIFICATION DIVISIONS................................6 
Appendix

2. COLLECTION PROFILES OF THE 500 AND 700 THROUGH 900

SUBJECT CATEGORIES....................................................................... 67

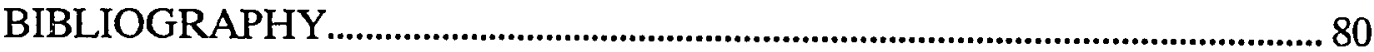




\section{LIST OF ILLUSTRATIONS}

Figure Page

1. Collection Profile for the 001-400 Categories (Branch R) ....................................53

2. Collection Profile for the 001-400 Categories (Branch L)......................................55

3. Collection Profile for the 001-400 Categories (Branch N) .....................................55

4. Collection Profile for the 600 Categories (Branch R)............................................57

5. Collection Profile for the 600 Categories (Branch L) ............................................58

6. Collection Profile for the 600 Categories (Branch N).........................................59

7. Collection Profile for the 500 Categories (Branch R)............................................66

8. Collection Profile for the 500 Categories (Branch L) ............................................69

9. Collection Profile for the 500 Categories (Branch N)........................................... 70

10. Collection Profile for the 700 Categories (Branch R) .............................................71

11. Collection Profile for the 700 Categories (Branch L) ...........................................72

12. Collection Profile for the 700 Categories (Branch N)..........................................73

13. Collection Profile for the 800 Categories (Branch R) ...........................................74

14. Collection Profile for the 800 Categories (Branch L) .......................................... 75

15. Collection Profile for the 800 Categories (Branch N)..........................................76

16. Collection Profile for the 900 Categories (Branch R)...........................................77

17. Collection Profile for the 900 Categories (Branch L) .........................................78

18. Collection Profile for the 900 Categories (Branch N)..........................................79 


\section{LIST OF TABLES}

Table

Page

1. Calculation of Desired Number of Items Compared to Current Holdings by Class (Branch R)........................................................34

2. Calculation of Desired Number of Items Compared to Current Holdings by Class (Branch L).....................................................36

3. Calculation of Desired Number of Items Compared to Current Holdings by Class (Branch N) .....................................................38

4. Composite C/D RATIO Analysis ...........................................................................4

5. ILL Compared to Holdings by Class (Branch R) .................................................4 42

6. Selection/Acquisitions Compared to Loans (Branch R)

7. Selection/Acquisitions Compared to Loans

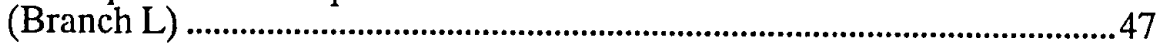

8. Selection/Acquisitions Compared to Loans

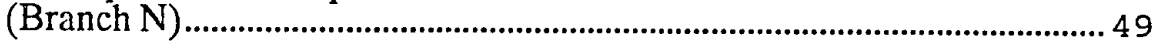

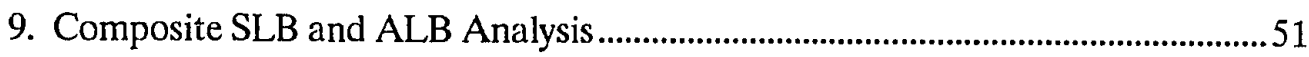




\section{CHAPTER 1}

\section{INTRODUCTION}

The benefits to be realized through collection assessment are widely acknowledged in the professional literature, yet for most public libraries with limited staff and resources, the labor intensive nature of the process has limited the effort. Evaluation and selection are usually based on informal observation and perceptions of patron preferences, reliance on "authoritative" reviews in the professional literature, and training in the standard selection criteria used to determine a "good" book. Selection frequently is made by title and is influenced by an individual's familiarity with her collection. The time-consuming exercise of collection evaluation, however, is irregular and infrequent. Space limitations sometimes provide the only real incentive to review the collection for less desirable titles, so designated either because they haven't circulated in some years, or because they aren't included in one of the standard bibliographies. Practical means to accomplish these tasks on a systematic and objective basis, much less combine them into an interrelated program of collection management have remained out of reach.

Two fundamental changes have occurred in public libraries in the last 20 years that may overcome some of the barriers to the development of such a program, the first being the automation of many library activities including circulation and acquisitions. The second is the growing realization that the public library may not survive the rapid technological, economic and social changes taking place unless it 
can become more responsive to the local community and justify on a more objective basis its activities to the governmental bodies that provide funding.

The ease of acquiring statistics on a library's collection and circulation through automation has increased in the last decade, yet few authors have examined methods of effective utilization of this new abundance of statistical information in a meaningful, cost-effective way to evaluate how responsive a local public library's collection is to the needs of its users. A variety of factors can explain this lack of attention. Almost all of the research in the area has been directed toward the needs of academic libraries. Further, many public libraries still cannot easily provide the data needed even though many of their functions have been automated. Extracting such data requires a higher level of programming along with the staff time and expertise to produce it. Standardized guide lines for analysis of the data are also lacking. Few library managers are willing or able to accept the added work load that manually compiling and analyzing such data entails. Finally, public librarians have less incentive than their colleagues in an academic setting to conduct their own research, and the results might only present managers with additional problems.

Library administrators generally rely on the performance measures promoted by the Public Library Association which are presented in Output Measures for Public Libraries. ${ }^{1}$. Other evaluations of performance have been largely absent, even though the validity and reliability of many of the output measures, especially those relating to collections, have been seriously questioned. Evaluation of library services only fairly recently has shifted to output measures of performance, and

\footnotetext{
${ }^{1}$ Nancy Van House et al., Output Measures for Public Libraries, 2ed (Chicago: American Library Association, 1987).
} 
these were designed to be affordable, to be capable of use by small as well as large libraries, to require the least effort and yet still supply useful information. The limited budgets of libraries for evaluation activities, or possibly the limited interest on the part of their managers, were clearly recognized.

Another underlying cause for the neglect of this area is lingering over-emphasis on the archival role of the library despite the advances in electronic storage, the needs and interests of public library users, and the rapid rate at which information becomes outdated, particularly in the form of hard-cover books. The priority given this role implies that the public library has a purpose separate and beyond the use of the collection by its clients, that it exists, in fact, for its own sake. Such a view may be appropriate for a research library, but it mitigates against a dynamic perception of the collection. Other than for local history, this role is difficult for a public library to defend.

Related to the attitude that clings to the archival role for the public library is the old "quality" versus demand conflict. Part of this view requires that demand take a lower priority. The librarian assumes the role of arbiter of excellence; selection is based more on what "should" be in the library than on what is used or needed by the residents of its community. To give more serious attention to the interests of users perhaps suggests a diminished importance for the role of the librarian. Yet, giving more serious attention to the interests of the community does not exclude or diminish the importance of protecting intellectual freedom and insuring a balanced collection on significant social concerns. In one large library system which already has the technical capability to easily produce any of the data needed for a thorough analysis of the use and selection for its collection, the head of technical services responded that no one had asked for it, and, "anyway, acquisitions already 
does an excellent job." Ideally, a knowledgeable librarian familiar with a wide variety of subject areas and utilizing professional book reviews and other guides such as the Public Library Catalog can provide qualitatively good and representative materials in any particular subject. But such an exercise is sterile. Collection management without reference to the user provides no guidelines for the quantitative allocation of library resources between the various areas of the collection.

Perhaps the greatest impetus to the development and use of assessment techniques in public libraries will come from the fact of diminishing library budgets and the increasing need to justify library activities to funding bodies. For example, California's Proposition 85 Library Construction Program requires an evaluation of the library's collection and a discussion of collection development including justification for the size and types of collections based on previous as well as anticipated purchasing patterns, verifiable library use statistics and any applicable standards or guidelines.

However, there are as yet no practical manuals available describing a comprehensive and rational collection management program for public libraries. The few measures currently recommended provide inadequate procedures for data analysis, reporting, and presentation strategies. The use of measures is not automatically linked to a long-range planning process or integration into library decision making. What is needed are techniques for appraising need and identifying patterns of collection use, for developing target-focused goals and action strategies, for evaluating efforts, and for reporting results. Techniques that also supply actionable guidelines without involving labor-intensive analyses could 
significantly enhance the manageability as well as desirability of the collection assessment process.

Collection evaluation is generally understood to be concerned with the value of each item to its users compared to items not included. ${ }^{2,3}$ Frequency of use or number of recorded loans of a book was chosen as the index of value most appropriate for a study of public library collections.

According to ALA's 1989 Guide to the Evaluation of Librany Collections techniques can be classified by whether qualitative or quantitive methods are employed or whether they are collection-centered or use centered. With usecentered methods, the emphasis may be on the use and/or on the users. This study takes a quantitative approach to evaluation and focuses on use. An attempt is made to use the data generated by an automated circuiation system and to link the evaluation of the collection to selection/acquisition patterns to produce a collection profile which could become a useful collection management tool.

The analysis was also designed to suit the needs of a public library with limited shelf space, no storage capacity and a generally dwindling budget for material, staff, and, in particular, evaluation activities. It is recognized that the format chosen for presenting results is probably as crucial to the effectiveness of the evaluation as the analysis. The presentation must provide as much information as possible in a format that involves relatively little staff time to produce or comprehend. The

\footnotetext{
${ }^{2}$ F.W. Lancaster, If You Want to Evaluate Your Library, (Champaign, Ill.: University of Illinois, 1988): 17.

${ }^{3}$ Rose Mary Magrill and John Corbin, Acquisitions Management and Collection Development in Libaries, 2d ed., (Chicago: Amcrican Library Association, 1989): 234.
} 
results should then reveal the adequacy of a collection to meet the demands of its users and provide guidelines for making collection management decisions.

More specifically, a method was developed to evaluate the circulating adult collection of a public library in order to: 1) determine the desirable number of items for each interest category; 2) compare this number to the current number of items in each category; 3) establish a threshold for making collection development decisions; and, 4) verify the results with interlibrary loan activity. Finally, a method is presented to link this analysis of holdings and usage data to selection/acquisitions activity. The overall aim of this study is to advance the development of a clear, objective means of monitoring the collection over time and increasing library responsiveness to changes in patterns of demand.

Three branch libraries provided the data for the study. Subjective perceptions and informal observation of user preferences along with annual circulation figures for broad categories of the collection have guided collection management decisions including budget allocation and acquisitions. Overall responsibility for selecting titles for new buying lists from which individual branches may make purchases rests with collection development staff who have minimal public service responsibilities and little or no contact with branch patrons or collections. A materials selection policy exists for the entire library system stating objectives, responsibilities and standards, but collection management guidelines which would provide the necessary mechanisms to implement objectives or measure the achievement of service goals do not exist, nor is there a means of integrating the separate collection management tasks into a comprehensive program of analysis and control. 
The study that follows explores this fundamental question: Is an analysis of use based on objective data better at predicting patron preferences than inferences based on informal observations of patron behavior or reference primarily to standard selection criteria and subjective decisions? To answer this the statistical procedures developed for assessing the collections based on use should reveal significant differences between the desired and current number of items for specific interest categories and between usage patterns and selection/acquisition decisions. The results are expected to indicate that greater familiarity with branch library users will lead to smaller variations between patterns of selections and use, but without objective guidelines, substantial variations between holdings, acquisitions and use will occur. 


\section{CHAPTER 2}

\section{REVIEW OF THE LITERATURE}

A review of the recent professional literature dealing with the evaluation of public library collections based on usage suggests that the number of studies is quite limited. The comparative lack of attention to this subject in public libraries was also observed by a review of the literature done by Kohl in $1988 .{ }^{1}$ He found that out of 195 research articles on the topic of collection evaluation or selection only 14 dealt with collection management in public libraries. Charles McClure points out that public librarians seldom possess the background in research methods which would enable them to conduct or utilize such studies. ${ }^{2}$ Whether this is true or not, the rather complex and abstract models deveioped for selection and evaluation in academic libraries are generally of little practical value to the public librarian.

Not only is there a lack of research, it also appears that little evaluation occurs in practice as well. Recently Charles Robinson, Director of the Baltimore County Public Library, lamented:

Despite the marvelous ability of our computers to provide management information, for example, we continue to build our collections with almost complete disregard to their use by the public, especially in our larger libraries. We

${ }^{1}$ David F. Kohl, "Collection Development--An Overview of the Research," Collection Management 10 (1988): 1-13.

${ }^{2}$ Charles R. McClure, "Increasing the Usefulness of Research for Library Managers: Propositions, Issues, and Strategies," Library Trends 38 (Fall 1989): 284. 
seem to delight in spending our limited materiais budgets practically in inverse proportion to demand. 3

Practical applications of the theories and methods of collection assessment have been observed to be the exception even in academic libraries. Several studies have noted managerial resistance to using information supplied by automation. Evans and Beilby found that recorded examples of circulation data actually having an effect on acquisition/selection decisions are extremely rare. ${ }^{4}$ Olsgaard has speculated that information overload is one cause of resistance: "The problem comes from trying to interpret all of this information [generated by automated systems] in a rational, logical manner."5

There is, at least in principle, a recognition among some public librarians that use should be given a strong emphasis in collection management. Hamilton and Weech $^{6}$ in their survey of Illinois public librarians found strong agreement with statements reflecting this attitude. Some of these statements were: "the focus of the library's collection should be on the actual utility of the collection to its current users"; "a library should buy more books in a high-demand area than in an area in which there is little interest," and; "user demand should be the primary criterion for

52.

${ }^{3}$ Charles Robinson, "The Public Library Vanishes," Library Journal 117 (March 15, 1992):

${ }^{4}$ Glyn Evans \& Albert Beilby, "A Library Management Information System in a MultiCampus Environment," in Clinic on Library Applications of Data Processing, Library Automation as a Source of Management Information (Champaign, Ill.: University of Illinois, 1983), 166.

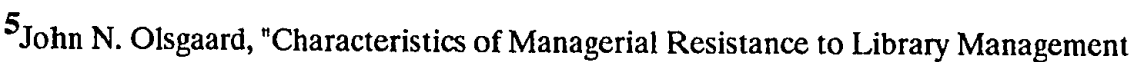
Information Systems," in Clinic on Library Applications of Data Processing, Library Automation as a Source of Management Information (Champaign, Ill.: University of Illinois, 1983): 166.

${ }^{6}$ Patricia Hamilton \& Terry Weech, "The Development and Testing of an Instrument to Measure Attitudes toward the Quality vs. Demand Debate in Collection Management," Collection Management 10 (1988): 27-42. 
buying books." The concept of supply and demand in a public library was introduced by Mostyn in an early study in which he also proposed using sampling techniques to make estimates before automation was widespread. ${ }^{7}$ Sharon Baker has discussed a noticeable trend especially in the last five years among some public librarians to adopt a marketing philosophy and design library collections "in response to patron needs and desires." 8 She also notes that numerous studies have demonstrated past popularity of a subject area to be a good predictor of future use.

Increasing emphasis on measures of use among some public libraries were stimulated by the publication of two manuals, Output Measures for Public Libraries (1982, 1987) and A Planning and Roles Setting Manual ${ }^{9}$ For purposes of evaluating a collection, title, author, and subject fill rate measures were advocated. D'Elia argues, however, that the procedures for measuring fill rates are not valid; too many uncontrolled factors intervene in these patron-reported measures of library performance. ${ }^{10}$

Although most collection management studies have been conducted in academic libraries, the concept of relative use or "the ratio of use to holdings in specific subject classes, both expressed as percentages of the respective totals"11

${ }^{7}$ Gregory Mostyn, "The Use of Supply-Demand Equality in Evaluating Collection Adequacy," California Librarian 35 (April 1974): 19.

${ }^{8}$ Sharon L. Baker, "Public Libraries," in Collection Management: A New Treatise, ed. Charles B. Osborn and Ross Atkinson, (Greenwich, CT: JAI Press, 1991), 395.

${ }^{9}$ Charles McClure et al, Planning and Role Setting for Public Libraries: A Manual of Options and Procedures (Chicago: American Library Association, 1987).

10 George D'Elia, "Materials Availability Fill Rates: Additional Data Addressing the Question of the Usefulness of the Measures," Public Libraries 27 (January/February 1988): 15-23.

11 George S.Bonn, "Evaluation of the Collection." Library Trends 22 (January 1974): 273. 
has been a common approach in one variation or another. Jain is credited with being the first to propose this concept. ${ }^{12}$ The American Library Association's latest Guide to the Evaluation of Library Collections ${ }^{\mathbf{1 3}}$ recommends it in describing use patterns based on circulation studies. The obvious means of analyzing use is to produce percentages for the different categories of the collection based on circulation data to establish absolute use. As Jain and others have noted, however, this method ignores the size of holdings for the various categories. A category with a larger percentage of items should be expected to have a larger percentage of the circulation on the basis of probability alone. Categories that have a circulation that exceeds or falls below what would be expected based on their proportion of the collection would be classified as overused or underused. Relative use, or the discrepancy between holdings and circulation, has been calculated in several ways, but beyond the assumption that the most deviant categories are in need of some kind of attention, this concept provides no further guidelines for making collection management decisions.

For smaller public libraries with limited shelf space, a method of calculating the desired stock for a given interesi category of a collection was proposed by A.W. McClellan who introduced the concept of shelf capacity in analyzing holdings and use data. ${ }^{14}$ The desired stock in a particular interest category is based on a ratio of the circulation of items in that category to the total circulation for all categories

${ }^{12}$ A.K. Jain, A Sampled Data Study of Book Usage in the Purdue University Libraries (Lafayette, IN: Purdue University, 1965). 1989), 9.

${ }^{13}$ Guide to the Evaluation of Library Collections (Chicago: American Library Association,

${ }^{14}$ A. W. McClellan, "Systematic Stock Control in Public Libraries," Ch. 8 in The Reader, the Library and the Book (London: Clive Bingley, 1973). 
multiplied by the total shelf capacity. Rather than absolute numbers, McClellan calculates the ratio using square roots. There are several advantages to this method: 1) total shelf capacity is factored into estimates for each category; 2) for libraries with changing space allocations, either expanding or declining, the method provides explicit goals for collection management; and, 3) the use of proportional representation by square root introduces controlled bias in favor of the smaller interest categories. According to McClellan this increases representation of these categories very substantially but without unduly reducing the range of choice in the larger interest categories. His method still sacrifices some of the control for collection bias that relative use measures provide. The influence that the size of holdings for any one category might have on circulation is not accounted for, but total size or potential size of a broad holdings category, such as adult non-fiction is included in calculations. In addition, unlike relative use, McClellan's method provides clear, concrete guidelines for managing a collection.

Other authors have recommended a number of ways an analysis of the statistical relationship between holdings and circulation should be supplemented. Merritt suggests that the relationship, along with acquisitions, should be considered over time "to discover whether certain changes in emphasis might not be in order."15 Lancaster makes the same recommendations by suggesting that librarians should supplement relative use statistics with a comparison to percent of current acquisitions. He also recommends a comparison of the latest year's circulation with

\footnotetext{
Co., 1970), 57.

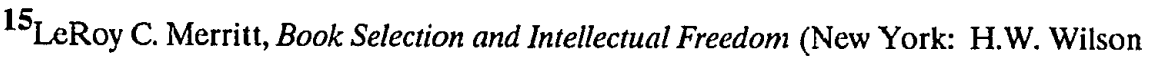


that of the previous year. ${ }^{16}$ Aguilar suggests supplementing relative use or "percentage of expecied use" statistics with interlibrary loan data to inform and verify the conclusions drawn from these statistics. ${ }^{17}$

There are limitations to the use of circulation data alone as a basis for collection management decisions. As Magrill and Corbin point out, "circulation data provide no information on the needs of those who choose not to come to the library or of those who come but cannot find what they want."18 Nevertheless, as a measure of an item's worth to the library's collection, such data are essential to an evaluation and can reveal actual use patterns. For public libraries, circulation may not be the only measure of effectiveness, but it is widely judged to be the most important. The overall mission and social purpose of the agency must be specifically defined to prevent an exclusive emphasis on this measure. Another limitation to circulation studies based on classification categories is the variation in cataloging practices that occurs over time. Major changes between different editions of the Dewey Classification System have been made for certain categories. Circulation data may also be distorted somewhat if significant shelf bias ${ }^{19}$ or collection bias ${ }^{\mathbf{2 0}}$ is present for a given category. The more overused the category, the more likely a particular

\footnotetext{
${ }^{17}$ William Aguilar, "The Application of Relative Use and Interlibrary Demand in Collection Development." Collection Management 8 (Spring 1986): 15-23.

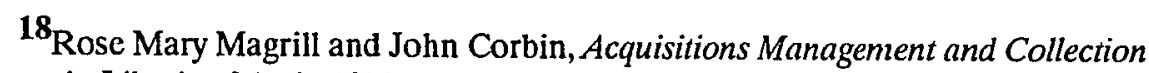
Development in Libaries, 2d ed., (Chicago: American Library Association, 1989), 241.

${ }^{19}$ Lancaster, 41.

${ }^{20} \mathrm{M}$. K. Buckland et al, "Methodological problems in Assessing the Overlap Between Bibliographic Files and Library Holdings," Information Processing and Management 11 (1975): 89 105.
}

${ }^{16}$ F.W. Lancaster, If You Want to Evaluate Your Library (Champaign, Ill.: University of Illinois, 1988), 43. 
item will be unavailable to a borrower. Selection is reduced, and only the less desirable items will be present most of the time.

Circulation studies also do not take into account in-library use. While it has been found to be true that total use will be under counted by relying exclusively on circulation data, particularly in an academic library, determining what is being used is generally of far more value in collection management than how much the library is being used. In branch public libraries, the proportion of non-circulating items is quite small. Furthermore, as Lancaster argues, "if one excludes items that are not allowed to leave the library, there is no real reason to suppose that the items used within a library will be much different from those borrowed. ${ }^{21}$ A number of studies have provided evidence that this is, in fact, the case. Hardesty found that books which had never circulated were in such pristine condition when examined that it was obvious they had "remained virtually untouched within the library."22 Other studies have demonstrated a significant correlation between the subject matter of books circulated and used in-house including Lawrence and Oja, ${ }^{23}$ Fussler and Simon, ${ }^{24}$ McGrath, ${ }^{25}$ Hindle and Buckland, ${ }^{26}$ Domas, ${ }^{27}$ and Bommer ${ }^{28}$.

${ }^{21}$ Lancaster, 52.

${ }^{\mathbf{2 2}}$ L. Hardesty. "Use of Library Materials at a Small Liberal Arts College," Library Research 3 ((1982): 265.

${ }^{23}$ G.S. Lawrence and A.R. Oja, The Use of General Collections at the University of California (Sacramento: California State Department of Education, 1980).

${ }^{24}$ H.H. Fussler and J.L. Simon, Patterns in the Use of Books in Large Research Libraries (Chicago: University of Chicago Press, 1969).

${ }^{25}$ W. E. McGrath. "Correlating the Subjects of Books Taken Out of and Books Used Within an Open-Stack Library," College and Research Libraries 32 (1971): 280-285.

${ }^{26}$ A. Hindle and M.K. Buckland, "In-Library Book Usage in Relation to Circulation, Collection Management 2 (1978): 265-277. 
More recently, attention has been directed to the use of microcomputers and applicable software for collection analysis particularly in a small library setting. One procedure, developed for a small community college library, combined the statistics generated by a turnkey automated system with a database program on a microcomputer. ${ }^{29}$ In another proposal, use of spreadsheet programs was advocated. Anderson presented an example of a comparison of library holdings with the percent of circulation coming from specific subject areas. ${ }^{30}$ He points out that a spreadsheet not only can reduce the time spent on calculations, results also can be read by word processors and incorporated into textual reports. Spreadsheet graphics are another important advantage. A graph combined with tables highlights and presents results in a generally more visually interesting and quickly understood format. Loertscher has proposed the concept of "collection mapping" as a means of meeting the goals of a school library media center. ${ }^{31}$ Although his method of analysis is not appropriate for a public library, part of the

${ }^{27}$ R.E. Domas, Correlating the Classes of Books Taken OUt of and Books Used Within an Open-Stack Library, (San Antonio: San Antonio College Library, 1978.

${ }^{28}$ M.R.W. Bommer, The Development of a Management System for Effective Decision Making and Planning in a University LIbrary (Philadelphia: University of Pennsylvania, Wharton School of Finance and Commerce, 1973).

${ }^{29}$ Robert K. Baker, "Using a Turnkey Automated System to Support Collection Assessment." College and Research Libraries 51 (July 1990): 360-366.

${ }^{30}$ Charles Anderson, "Using Tecinnology: Spreadsheet Programs and Collection Development." Wilson Library Bulletin 65 (September 1990): 90-94.

${ }^{31}$ David V. Loertscher, "Collection Mapping: An Evaluation Strategy for Collection Development," Drexel Library Quarterly 21 (Spring 1985): 12. 
process involves constructing a graphic representation of the results of his evaluation which can then easily be compared to other aspects of his analysis.

To be useful to library managers, McClure suggests that "research must be uncomplicated, specify implementation strategies, and solve problems."132 Research results must not only identify a problem and its solution, but must also include specific practical steps to implement findings. The methods, the technology, and at least some of the data finally are available to make feasible the development of a more rational and responsive program of collection management and evaluation for public libraries.

${ }^{32}$ McClure, "Increasing the Usefulness of Research for Library Managers," 285. 


\section{CHAPTER 3}

\section{METHODOLOGY}

The collection management techniques developed for this study are based on an evaluation of use, holdings, inter-library loans, and selection/acquisitions. First an analysis of use and holdings data was conducted to determine the desirable number of items for each interest category. The technique is derived from McClellan's proposal which introduced the concept of shelf capacity in performing such an analysis. ${ }^{1}$ Second, the desired number was compared to the current number of items in each category and a threshold established based on standard deviation scores for determining those categories in need of further attention. Third, based on Aguilar's recommendation, ${ }^{2}$ the results were supplemented with interlibrary loan data to verify the findings and provide guidelines for making collection management decisions. Finally, selection/acquisitions data is collected for each category and compared to use.

The results of this analysis are graphically represented to produce a collection profile. A spreadsheet (QuattroPro) was used to facilitate calculations and provide a quick method of graphing the data. The final result should reveal areas of the collection where substantial variations exist between patterns of use and selections

${ }^{1}$ McClellan, 86-88.

${ }^{2}$ Aguilar, 20. 
and/or size of holdings and provide a basis for directing management of a branch public library collection.

\section{Collection Analysis}

A.W. McClellan proposed a method for determining the desired stock in a particular interest category based on a ratio of the circulation or number of loans in a designated category, in this case defined by the Dewey divisions by tens, to the total circulation using the square root of the numbers rather than raw totals. This method can be represented by the following formula:

$$
\begin{gathered}
\frac{\sqrt{\text { circulation of interest category }}}{\Sigma \sqrt{\text { all categories }}} \times \text { total shelf capacity } \\
=\text { Desired stock for category. }
\end{gathered}
$$

The principle disadvantage of this approach is the lack of control for shelf bias and its effects on circulation. Other methods, such as Jain's calculation of relative use, can account for this bias, but they do not account for the limits or change in shelf capacity.

The next step is to find the ratio between the desired and current number of items by dividing current holdings by the desired number (C/D Ratio). Yet, this still does not provide explicit guidelines for making collection management decisions. For this purpose, the mean and standard deviation (SD) of the C/D Ratio is calculated in order to obtain standard scores ( $Z$ scores) for each category. ${ }^{3}$ Any category that would have a standard normal probability of falling more than 33

\footnotetext{
3 To convert the difference score for a category into standard deviation units, the mean is subtracted from the score and the result divided by the SD.
} 
percent above or below the mean of difference scores should be a candidate for additional evaluation. This would be represented by a $Z$ score of \pm 1.00 . A score 1 SD below the mean for a particular subject would indicate underrepresentation of items; a score $1 \mathrm{SD}$ above the mean would suggest overrepresentation for that category. Z Scores based on the C/D Ratio are an internally based measure sensitive to the holdings and use patterns of each branch. The mean and standard deviaton is expected to vary by branch.

To provide additional refinement and verification of the results obtained from circulation and holdings data, interlibrary loan (ILL) activity is analyzed relative to holdings following Aguilar's recommended procedure:

$$
\frac{\% \text { of ILL }}{\% \text { of Holdings }}=\text { Ratio of ILL to Holdings }
$$

The same statistical method is then applied to the result to obtain $\mathrm{Z}$ scores for interlibrary loans. This part of the analysis was restricted to the one branch able to provide the ILL data by classification category.

A graphic presentation of the $\mathrm{Z}$ scores obtained for the collection and interlibrary loan activity produces a collection profile that can quickly highlight the interest categories in need of corrective action. In an underrepresented category with a high ILL/Holdings ratio, the need to purchase additional and possibly duplicate items is indicated. Where local materials are overrepresented, but the ILL/Holdings ratio is still high, a closer examination of the collection should be made for inappropriate items. In the case of an overrepresented category and a low ILL/Holdings ratio, it is possible that additional purchasing in this area should be curtailed, but for a small collection with an overall low use of interlibrary loan services, such a conclusion should be kept tentative. A re-examination of the 
collection on this subject would still be recommended. Finally, an underrepresented category with a low ILL/Holdings ratio would suggest that the right materials are being selected, but there are not enough copies to satisfy the demand.

\section{Selection/Acquisitions Analysis}

The proportion of selections of new titles by collection development staff and acquisitions by branch are compared with the proportion of loans for each collection category by branch. The differences in proportions are calculated by class, and those classes exceeding \pm 1 are targeted as most in need of attention by either or both branch and collection development staff. These calculations are represented as follows:

Percentage of new selections - percentage of loans by branch $=$ Selection/Loan Balance (SLB).

Percentage of acquisitions - percentage of loans by branch $=$ Acquisition/Loan Balance (ALB).

A value greater than +1 indicates a high level of selections or acquisitions relative to use. A value less than -1 indicates selections and/or acquisitions below the level of use. Fewer subject categories are expected to fall into this range for acquisitions made by each branch than for selections made by non-branch staff.

\section{Collection Profile}

The results of the collection and selection/acquisitions analyses are compared by category to produce a collection profile. The profile is graphically presented to reveal overall patterns and deviations from those patterns and should indicate in what areas to redirect collection management efforts. The ideal profile is a straight 
line with all measures at 0 . For a subject class, the $\mathrm{Z}$ Scores for the collection analysis measures would be 0 , if the Ratios were at the means. The Selection/Acquisitions measures would also be 0 , if there were no differences between the percentages of use and acquisitions and selections.

A number of combinations for the results of the measures for each class are possible. The outcomes of the analyses, and the actions that are indicated in a comprehensive collection management program can be summarized as follows:

\begin{tabular}{cccc}
\hline Collection Analysis & \multicolumn{3}{c}{$\begin{array}{c}\text { Selection/Acquisitions } \\
\text { Analysis }\end{array}$} \\
C/D RATIO & ALB & SLB & OUTCOME \\
\hline H & H & H & 1 \\
H & H & L & 2 \\
H & L & L & 3 \\
H & L & H & 4 \\
L & L & L & 5 \\
L & H & H & 6 \\
L & L & H & 7 \\
L & H & L & 8 \\
\hline
\end{tabular}

For each outcome, decision guidelines can be formulated: 1. Acquisitions and selections are high in an already overrepresented category. Weeding, a lower level of purchasing, and modified development are recommended. 
2. The category is overrepresented and acquisitions are high, but selection of new titles is weak compared to use. Weeding, reduced purchasing, and a reevaluation of the development of this subject area is advisable.

3. Too many items suggests weeding in this category is necessary, but low selection and purchasing levels may be appropriate to correct the imbalance, although it could also indicate that title selection should be re-evaluated.

4. The collection is overrepresented in this class and selections are higher than needed, but low acquisitions along with weeding may correct the imbalance.

5. Low levels on all measures clearly point to the need for greatly increased levels of purchasing and development of this subject class.

6. The category is underrepresented, but high levels of selection and acquisitions will probably correct this imbalance.

7. Although selections are high, acquisitions and the desired level of items are low. This outcome recommends a careful examination of the appropriateness of selected titles.

8. This is an underrepresented category, but high acquisitions may correct the imbalance. Selections are weak compared to use and should be increased.

It is unlikely, however, that all measures will exceed the threshold for one class. If a subject category exceeds the decision threshold for either the collection or selection/acquisitions analyses, that is cause for a closer examination and monitoring of that category over time. For example, if a collection analysis measure is low, acquisitions should probably be increased; if it is high, weeding is probably needed. If both the collection and selection/acquisition measure exceed the threshold, however, the decision guidelines can still be used. 


\section{Collection and Acquisitions Data}

Data was collected for three branches of a large public library system. The branches vary in size of annual circulation and the socio-economic level of the areas served. The largest branch (Branch L) is located within a middle-class suburban part of an incorporated city. Its annual (1990-91) circulation was 199,554 and its collection contains 57,961 items. Of these, nearly 17,000 are classed as adult circulating non-fiction. The second branch (Branch $\mathrm{R}$ ) had an annual circulation of 102,797 and contains 40,311 items with close to 10,000 of these belonging to the adult circulating non-fiction category. Branch $\mathrm{R}$ is located in a lower socioeconomic community. Branch $\mathrm{N}$ is located in a partly rural community with a very high socio-economic level and is noted for its dedication to the ownership of horses. This Branch had a total of 81,317 circulations and contains close to 11,000 adult non-fiction items out of a total of 36,170 .

The circulation system has been automated since 1984, but an analysis of holdings and circulation by Dewey division only became available recently when additional programming was completed. Interest categories are based on these divisions, and a description of each category can be found in Appendix 1. The division is by 10 's except for very small subject categories, both in terms of holdings and circulation, where a whole division was grouped together. These are the 001, 100 , and 200 classes. Classes with no items at a branch were dropped. Not surprisingly, the largest branch had the highest number of classes included in the analysis. For all three branches the 310,760 , and 870 classes, which had at most three items and no circulation or selections, were dropped. Circulation or loans for a particular class is defined as the total number of transactions occuring in the class 
in a one year period. Multiple loans of one item are each counted as one transaction.

The automated system is not yet able to produce the data needed for an analysis of acquisitions or interlibrary loan activity. Online ordering for each branch is being planned for the coming year, but for this study all tallying by interest category was done manually. A record of interlibrary loan titles was kept only by Branch $\mathrm{R}$, but interlibrary loan activity is minimal for this Branch, and a small fee $(\$ .50)$ is charged for each requested title. Nevertheless, the data was analyzed to further refine the assessment of the local collection at this Branch. If this activity should increase or the data becomes available at other branches with higher rates of activity such an analysis should then provide an even better indication of collection strengths and weaknesses.

Decisions concerning the kinds of analysis of the data that might be possible with additional programming have not been made by the library's management at this time, but explicit support for development of a "management information system" for the collection has been announced as part of the high priority given to increasing the quality and responsiveness to "customer" needs.

Acquisitions data were manually compiled from the new book and replacement buying lists for each branch. Collection development staff are primarily responsible for the titles appearing on the new book lists, although suggestions are welcome from other staff and the public. Titles on replacement lists are compiled from the requests sent to collection development staff by department and branch managers. The only basis for selection of these titles is the judgment of the public service staff who may or may not recognize a need for more titles on a certain subject or the need for more copies of a popular book. 
At the present time acquisition and selection data cannot be produced by the automated system. The acquisitions module supplied by the vendor (Data Research Associates) will be purchased in the coming year as well as the vendor's Report Writer, but neither of these additions will permit the production of the kind of data needed without some additional higher level of programming and data manipulation. Inquiry at other large public library systems revealed that none of them yet was either able or interested in generating such data. 


\section{CHAPTER 4}

\section{RESULTS}

\section{C/D Ratios}

The results of the analysis of use and holdings data for the three Branches are presented in Tables 1-3. The number of Dewey classes varies slightly for each Branch with the smallest Branch having the lowest number. Classes with no items were dropped. The number of loans made in a one year period are found in the second column. Applying McClellan's method, the square root of the transactions for a category $(\sqrt{ } n)$ are divided by the sum of the square roots for all categories to determine the percent loaned for each category which is found in the fourth column. The desired number for a category is then calculated by multiplying this loan factor by total shelf capacity. Next, the ratio between the current and desired number of

items is presented in the seventh column. Ratios with a $Z$ score $\geq+1$ or or $\leq-1$ are noted in the last column.

Branch R. This branch has nearly 10,000 adult non-fiction items and, during the study period, made 4,655 loans. Out of 60 classes ten categories were $\geq+1 \mathrm{SD}$ above the mean, and seven were $\leq-1$. The mean $\mathrm{C} / \mathrm{D}$ Ratio was .73 with a range between .17 and 2.00. With a SD of .44, a C/D Ratio of 1.17 would be one SD above the mean and a C/D Ratio of .29 would be one SD below the mean. 
Table 1.--Calculation of Desired Number of Items Compared to Current Holdings by Class (Branch R)

\begin{tabular}{|c|c|c|c|c|c|c|c|c|}
\hline CLASS & $\begin{array}{c}\text { Loans } \\
(x) \\
\end{array}$ & $\sqrt{x}$ & $\begin{array}{l}\% \text { Loaned } \\
(\sqrt{x} / \Sigma \sqrt{x})\end{array}$ & $\begin{array}{c}\text { Desired } \\
\text { No.(d) }\end{array}$ & $\begin{array}{l}\text { Current } \\
\text { No.(c) } \\
\end{array}$ & $c / d$ & $\begin{array}{c}Z \\
\text { Scores } \\
\end{array}$ & $\begin{array}{l} \pm 1 \\
S D \\
\end{array}$ \\
\hline 000 & 93 & 9.64 & 2.17 & 217 & 256 & 1.18 & 1.02 & Yes \\
\hline 100 & 193 & 13.89 & 3.13 & 313 & 397 & 1.27 & 1.23 & Yes \\
\hline 200 & 110 & 10.49 & 2.36 & 236 & 246 & 1.04 & 0.71 & 0 \\
\hline 300 & 133 & 11.53 & 2.59 & 259 & 270 & 1.04 & 0.71 & 0 \\
\hline 320 & 43 & 6.56 & 1.48 & 148 & 112 & 0.76 & 0.07 & 0 \\
\hline 330 & 100 & 10.00 & 2.25 & 225 & 249 & 1.11 & 0.86 & 0 \\
\hline 340 & 110 & 10.49 & 2.36 & 236 & 239 & 1.01 & 0.64 & 0 \\
\hline 350 & 61 & 7.81 & 1.76 & 176 & 131 & 0.75 & 0.04 & 0 \\
\hline 360 & 215 & 14.66 & 3.30 & 330 & 468 & 1.42 & 1.57 & Yes \\
\hline 370 & 90 & 9.49 & 2.13 & 213 & 172 & 0.81 & 0.17 & 0 \\
\hline 380 & 18 & 4.24 & 0.95 & 95 & 51 & 0.53 & -0.44 & 0 \\
\hline 390 & 55 & 7.42 & 1.67 & 167 & 107 & 0.64 & -0.20 & 0 \\
\hline 400 & 59 & 7.68 & 1.73 & 173 & 135 & 0.78 & 0.12 & 0 \\
\hline 500 & 25 & 5.00 & 1.12 & 112 & 41 & 0.36 & -0.83 & 0 \\
\hline 510 & 34 & 5.83 & 1.31 & 131 & 68 & 0.52 & -0.48 & 0 \\
\hline 520 & 23 & 4.80 & 1.08 & 108 & 53 & 0.49 & -0.54 & 0 \\
\hline 530 & 14 & 3.74 & 0.84 & 84 & 27 & 0.32 & -0.93 & 0 \\
\hline 540 & 9 & 3.00 & 0.67 & 67 & 16 & 0.24 & -1.12 & Yes \\
\hline 550 & 46 & 6.78 & 1.53 & 153 & 63 & 0.41 & -0.72 & 0 \\
\hline 560 & 10 & 3.16 & 0.71 & 71 & 12 & 0.17 & -1.28 & Yes \\
\hline 570 & 38 & 6.16 & 1.39 & 139 & 101 & 0.73 & -0.00 & 0 \\
\hline 580 & 12 & 3.46 & 0.78 & 78 & 32 & 0.41 & -0.73 & 0 \\
\hline 590 & 82 & 9.06 & 2.04 & 204 & 133 & 0.65 & -0.18 & 0 \\
\hline 600 & 8 & 2.83 & 0.64 & 64 & 19 & 0.30 & -0.98 & 0 \\
\hline 610 & 428 & 20.69 & 4.65 & 465 & 777 & 1.67 & 2.14 & Yes \\
\hline 620 & 103 & 10.15 & 2.28 & 228 & 199 & 0.87 & 0.32 & 0 \\
\hline 630 & 284 & 16.85 & 3.79 & 379 & 431 & 1.14 & 0.92 & 0 \\
\hline 640 & 324 & 18.00 & 4.05 & 405 & 617 & 1.52 & 1.80 & Yes \\
\hline 650 & 152 & 12.33 & 2.77 & 277 & 307 & 1.11 & 0.86 & 0 \\
\hline 660 & 5 & 2.24 & 0.50 & 50 & 18 & 0.36 & -0.85 & 0 \\
\hline 670 & 10 & 3.16 & 0.71 & 71 & 16 & 0.22 & -1.15 & Yes \\
\hline 680 & 65 & 8.06 & 1.81 & 181 & 136 & 0.75 & 0.05 & 0 \\
\hline 690 & 55 & 7.42 & 1.67 & 167 & 113 & 0.68 & -0.12 & 0 \\
\hline
\end{tabular}


Table 1-- continued

\begin{tabular}{|c|c|c|c|c|c|c|c|c|}
\hline CLASS & $\begin{array}{c}\text { Loans } \\
(x) \\
\end{array}$ & $\sqrt{x}$ & $\begin{array}{l}\% \text { Loaned } \\
(\sqrt{x} / \Sigma \sqrt{x})\end{array}$ & $\begin{array}{c}\text { Desired } \\
\text { No.(d) }\end{array}$ & $\begin{array}{l}\text { Current } \\
\text { No.(c) }\end{array}$ & $c / d$ & $\begin{array}{c}Z \\
\text { Scores } \\
\end{array}$ & $\begin{array}{l} \pm 1 \\
S D \\
\end{array}$ \\
\hline 700 & 16 & 4.00 & 0.90 & 90 & 52 & 0.58 & -0.35 & 0 \\
\hline 710 & 14 & 3.74 & 0.84 & 84 & 25 & 0.30 & -0.98 & 0 \\
\hline 720 & 22 & 4.69 & 1.06 & 106 & 60 & 0.57 & -0.37 & 0 \\
\hline 730 & 36 & 6.00 & 1.35 & 135 & 76 & 0.56 & -0.38 & 0 \\
\hline 740 & 189 & 13.75 & 3.09 & 309 & 407 & 1.32 & 1.33 & Yes \\
\hline 750 & 13 & 3.61 & 0.81 & 81 & 35 & 0.43 & -0.68 & 0 \\
\hline 770 & 10 & 3.16 & 0.71 & 71 & 40 & 0.56 & -0.38 & 0 \\
\hline 780 & 73 & 8.54 & 1.92 & 192 & 155 & 0.81 & 0.17 & 0 \\
\hline 790 & 238 & 15.43 & 3.47 & 347 & 608 & 1.75 & 2.32 & Yes \\
\hline 800 & 67 & 8.19 & 1.84 & 184 & 145 & 0.79 & 0.13 & 0 \\
\hline 810 & 25 & 5.00 & 1.12 & 112 & 63 & 0.56 & -0.39 & 0 \\
\hline 820 & 132 & 11.49 & 2.58 & 258 & 383 & 1.48 & 1.71 & Yes \\
\hline 830 & 2 & 1.41 & 0.32 & 32 & 9 & 0.28 & -1.02 & Yes \\
\hline 840 & 5 & 2.24 & 0.50 & 50 & 16 & 0.32 & -0.94 & 0 \\
\hline 860 & 1 & 1.00 & 0.22 & 22 & 7 & 0.31 & -0.95 & 0 \\
\hline 880 & 4 & 2.00 & 0.45 & 45 & 12 & 0.27 & -1.05 & Yes \\
\hline 890 & 6 & 2.45 & 0.55 & 55 & 26 & 0.47 & -0.59 & 0 \\
\hline 900 & 7 & 2.65 & 0.60 & 60 & 23 & 0.39 & -0.78 & 0 \\
\hline 910 & 221 & 14.87 & 3.34 & 334 & 488 & 1.46 & 1.66 & Yes \\
\hline 920 & 263 & 16.22 & 3.65 & 365 & 731 & 2.00 & 2.89 & Yes \\
\hline 930 & 23 & 4.80 & 1.08 & 108 & 35 & 0.32 & -0.92 & 0 \\
\hline 940 & 116 & 10.77 & 2.42 & 242 & 215 & 0.89 & 0.36 & 0 \\
\hline 950 & 27 & 5.20 & 1.17 & 117 & 52 & 0.44 & -0.65 & 0 \\
\hline 960 & 4 & 2.00 & 0.45 & 45 & 12 & 0.27 & -1.05 & Yes \\
\hline 970 & 128 & 11.31 & 2.55 & 255 & 250 & 0.98 & 0.57 & 0 \\
\hline 980 & 4 & 2.00 & 0.45 & 45 & 10 & 0.22 & -1.15 & Yes \\
\hline 990 & 2 & 1.41 & 0.32 & 32 & 15 & 0.47 & -0.59 & 0 \\
\hline $\begin{array}{l}\text { TOTAL } \\
(n=60)\end{array}$ & 4655 & 444.54 & 100.00 & 10000 & 9962 & & & 17 \\
\hline mean & & & & & & 0.73 & & \\
\hline sd & & & & & & 0.44 & & \\
\hline $\min$ & & & & & & 0.17 & & \\
\hline $\max$ & & & & & & 2.00 & & \\
\hline
\end{tabular}


Table 2.--Calculation of Desired Number of Items Compared to Current Holdings by Class (Branch L)

\begin{tabular}{|c|c|c|c|c|c|c|c|c|}
\hline CLASS & $\begin{array}{l}\text { Loans } \\
(x)\end{array}$ & $\sqrt{x}$ & $\begin{array}{l}\text { \% Loaned } \\
(\sqrt{x} / \Sigma \sqrt{x})\end{array}$ & $\begin{array}{c}\text { Desired } \\
\text { No.(d) }\end{array}$ & $\begin{array}{l}\text { Current } \\
\text { No.(c) }\end{array}$ & $\mathrm{c} / \mathrm{d}$ & $\begin{array}{c}Z \\
\text { Scores }\end{array}$ & $\begin{array}{l} \pm 1 \\
\text { SD }\end{array}$ \\
\hline 000 & 260 & 16.12 & 2.53 & 430 & 439 & 1.02 & 0.67 & 0 \\
\hline 100 & 362 & 19.03 & 2.99 & 508 & 601 & 1.18 & 1.03 & Yes \\
\hline 200 & 286 & 16.91 & 2.65 & 451 & 493 & 1.09 & 0.83 & 0 \\
\hline 300 & 306 & 17.49 & 2.75 & 467 & 551 & 1.18 & 1.02 & Yes \\
\hline 320 & 120 & 10.95 & 1.72 & 292 & 231 & 0.79 & 0.16 & 0 \\
\hline 330 & 227 & 15.07 & 2.36 & 402 & 397 & 0.99 & 0.59 & 0 \\
\hline 340 & 171 & 13.08 & 2.05 & 349 & 303 & 0.87 & 0.33 & 0 \\
\hline 350 & 87 & 9.33 & 1.46 & 249 & 179 & 0.72 & -0.00 & 0 \\
\hline 360 & 403 & 20.07 & 3.15 & 536 & 702 & 1.31 & 1.31 & Yes \\
\hline 370 & 182 & 13.49 & 2.12 & 360 & 292 & 0.81 & 0.20 & 0 \\
\hline 380 & 52 & 7.21 & 1.13 & 192 & 92 & 0.48 & -0.54 & 0 \\
\hline 390 & 114 & 10.68 & 1.68 & 285 & 155 & 0.54 & -0.39 & 0 \\
\hline 400 & 106 & 10.30 & 1.62 & 275 & 210 & 0.76 & 0.10 & 0 \\
\hline 500 & 29 & 5.39 & 0.85 & 144 & 59 & 0.41 & -0.69 & 0 \\
\hline 510 & 45 & 6.71 & 1.05 & 179 & 81 & 0.45 & -0.59 & 0 \\
\hline 520 & 74 & 8.60 & 1.35 & 230 & 92 & 0.40 & -0.71 & 0 \\
\hline 530 & 13 & 3.61 & 0.57 & 96 & 22 & 0.23 & -1.09 & Yes \\
\hline 540 & 10 & 3.16 & 0.50 & 84 & 17 & 0.20 & -1.15 & Yes \\
\hline 550 & 62 & 7.87 & 1.24 & 210 & 90 & 0.43 & -0.65 & 0 \\
\hline 560 & 18 & 4.24 & 0.67 & 113 & 23 & 0.20 & -1.15 & Yes \\
\hline 570 & 106 & 10.30 & 1.62 & 275 & 202 & 0.74 & 0.03 & 0 \\
\hline 580 & 58 & 7.62 & 1.20 & 203 & 72 & 0.35 & -0.81 & 0 \\
\hline 590 & 159 & 12.61 & 1.98 & 336 & 285 & 0.85 & 0.28 & 0 \\
\hline 600 & 13 & 3.61 & 0.57 & 96 & 28 & 0.29 & -0.95 & 0 \\
\hline 610 & 839 & 28.97 & 4.55 & 773 & 1310 & 1.70 & 2.17 & Yes \\
\hline 620 & 153 & 12.37 & 1.94 & 330 & 314 & 0.95 & 0.51 & 0 \\
\hline 630 & 437 & 20.90 & 3.28 & 558 & 667 & 1.20 & 1.06 & Yes \\
\hline 640 & 634 & 25.18 & 3.95 & 672 & 1027 & 1.53 & 1.80 & Yes \\
\hline 650 & 209 & 14.46 & 2.27 & 386 & 396 & 1.03 & 0.68 & 0 \\
\hline 660 & 9 & 3.00 & 0.47 & 80 & 33 & 0.41 & -0.68 & 0 \\
\hline 670 & 16 & 4.00 & 0.63 & 107 & 25 & 0.23 & -1.08 & Yes \\
\hline 680 & 89 & 9.43 & 1.48 & 252 & 152 & 0.60 & -0.26 & 0 \\
\hline 690 & 100 & 10.00 & 1.57 & 267 & 156 & 0.58 & -0.30 & 0 \\
\hline 700 & 36 & 6.00 & 0.94 & 160 & 83 & 0.52 & -0.45 & 0 \\
\hline
\end{tabular}


Table 2--Continued

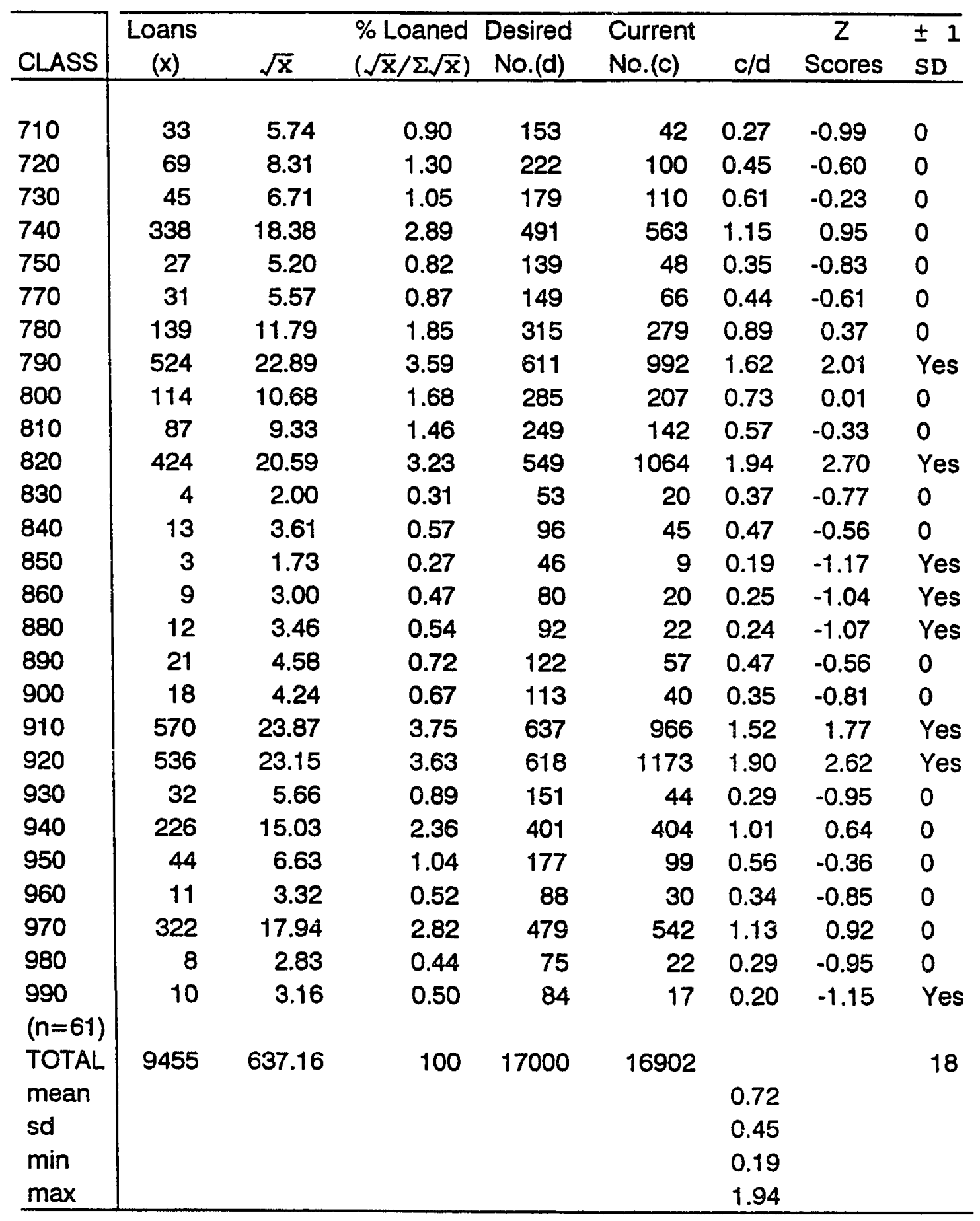


Table 3.--Calculation of Desired Number of Items Compared to Current Holdings by Class (Branch $\mathrm{N}$ )

\begin{tabular}{|c|c|c|c|c|c|c|c|c|}
\hline Class & $\begin{array}{l}\text { Loans } \\
(x)\end{array}$ & $\sqrt{x}$ & $\begin{array}{l}\text { \% Loaned } \\
(\sqrt{x} / \Sigma \sqrt{x})\end{array}$ & $\begin{array}{l}\text { Desired } \\
\text { No. (d) }\end{array}$ & $\begin{array}{l}\text { Current } \\
\text { No. (c) }\end{array}$ & $c / d$ & $\begin{array}{c}Z \\
\text { Scores }\end{array}$ & $\begin{array}{l} \pm 1 \\
S D\end{array}$ \\
\hline 000 & 138 & 11.75 & 2.62 & 288 & 375 & 1.30 & 1.35 & Yes \\
\hline 100 & 238 & 15.43 & 3.44 & 379 & 425 & 1.12 & 0.96 & 0 \\
\hline 200 & 84 & 9.17 & 2.05 & 225 & 196 & 0.87 & 0.40 & 0 \\
\hline 300 & 88 & 9.38 & 2.09 & 230 & 237 & 1.03 & 0.75 & 0 \\
\hline 320 & 38 & 6.16 & 1.38 & 151 & 98 & 0.65 & -0.09 & 0 \\
\hline 330 & 111 & 10.54 & 2.35 & 259 & 230 & 0.89 & 0.44 & 0 \\
\hline 340 & 90 & $\overline{9} .49$ & 2.12 & 233 & 161 & 0.69 & 0.01 & 0 \\
\hline 350 & 32 & 5.66 & 1.26 & 139 & 94 & 0.68 & -0.02 & 0 \\
\hline 360 & 200 & 14.14 & 3.16 & 347 & 387 & 1.11 & 0.94 & 0 \\
\hline 370 & 89 & 9.43 & 2.11 & 232 & 175 & 0.76 & 0.15 & 0 \\
\hline 380 & 19 & 4.36 & 0.97 & 107 & 51 & 0.48 & -0.46 & 0 \\
\hline 390 & 51 & 7.14 & 1.59 & 175 & 100 & 0.57 & -0.26 & 0 \\
\hline 400 & 52 & 7.21 & 1.61 & 177 & 116 & 0.66 & -0.07 & 0 \\
\hline 500 & 17 & 4.12 & 0.92 & 101 & 39 & 0.39 & -0.66 & 0 \\
\hline 510 & 33 & 5.74 & 1.28 & $\mathfrak{i} 41$ & 60 & 0.43 & -0.57 & 0 \\
\hline 520 & 38 & 6.16 & 1.38 & 151 & 61 & 0.40 & -0.62 & 0 \\
\hline 530 & 9 & 3.00 & 0.67 & 74 & 21 & 0.29 & -0.88 & 0 \\
\hline 540 & 1 & 1.00 & 0.22 & 25 & 6 & 0.24 & -0.97 & 0 \\
\hline 550 & 39 & 6.24 & 1.39 & 153 & 59 & 0.38 & -0.66 & 0 \\
\hline 560 & 11 & 3.32 & 0.74 & 81 & 15 & 0.18 & -1.11 & Yes \\
\hline 570 & 37 & 6.08 & 1.36 & 149 & 132 & 0.88 & 0.43 & 0 \\
\hline 580 & 14 & 3.74 & 0.84 & 92 & 37 & 0.40 & -0.62 & 0 \\
\hline 590 & 114 & 10.68 & 2.38 & 262 & 199 & 0.76 & 0.16 & 0 \\
\hline 600 & 17 & 4.12 & 0.92 & 101 & 21 & 0.21 & -1.05 & Yes \\
\hline 610 & 397 & 19.92 & 4.45 & 489 & 796 & 1.63 & 2.07 & Yes \\
\hline 620 & 111 & 10.54 & 2.35 & 259 & 201 & 0.78 & 0.20 & 0 \\
\hline 630 & 622 & 24.94 & 5.57 & 612 & 1069 & 1.75 & 2.33 & Yes \\
\hline 640 & 378 & 19.44 & 4.34 & 477 & 877 & 1.84 & 2.53 & Yes \\
\hline 650 & 185 & 13.60 & 3.04 & 334 & 277 & 0.83 & 0.31 & 0 \\
\hline 660 & 7 & 2.65 & 0.59 & 65 & 21 & 0.32 & -0.80 & 0 \\
\hline 670 & 8 & 2.83 & 0.63 & 69 & 20 & 0.29 & -0.88 & 0 \\
\hline 680 & 63 & 7.94 & 1.77 & 195 & 140 & 0.72 & 0.07 & 0 \\
\hline 690 & 77 & 8.77 & 1.96 & 215 & 136 & 0.63 & -0.12 & 0 \\
\hline
\end{tabular}


Table 3-- Continued

\begin{tabular}{|c|c|c|c|c|c|c|c|c|}
\hline Class & $\begin{array}{c}\text { Loans } \\
(x)\end{array}$ & $\sqrt{x}$ & $\begin{array}{l}\text { \% Loaned } \\
(\sqrt{x} / \Sigma \sqrt{x})\end{array}$ & $\begin{array}{c}\text { Desired } \\
\text { No. (d) }\end{array}$ & $\begin{array}{l}\text { Current } \\
\text { No. (c) }\end{array}$ & $c / d$ & $\begin{array}{c}\mathrm{Z} \\
\text { Scores }\end{array}$ & $\begin{array}{l} \pm 1 \\
\mathrm{SD}\end{array}$ \\
\hline 700 & 15 & 3.87 & 0.86 & 95 & 32 & 0.34 & -0.77 & 0 \\
\hline 710 & 29 & 5.39 & 1.20 & 132 & 37 & 0.28 & -0.89 & 0 \\
\hline 720 & 48 & 6.93 & 1.55 & 170 & 86 & 0.51 & -0.40 & 0 \\
\hline 730 & 27 & 5.20 & 1.16 & 128 & 59 & 0.46 & -0.49 & 0 \\
\hline 740 & 268 & 16.37 & 3.65 & 402 & 486 & 1.21 & 1.15 & Yes \\
\hline 750 & 13 & 3.61 & 0.80 & 89 & 31 & 0.35 & -0.74 & 0 \\
\hline 770 & 30 & 5.48 & 1.22 & 134 & 49 & 0.36 & -0.71 & 0 \\
\hline 780 & 75 & 8.66 & 1.93 & 213 & 155 & 0.73 & 0.09 & 0 \\
\hline 790 & 391 & 19.77 & 4.41 & 486 & 902 & 1.86 & 2.57 & Yes \\
\hline 800 & 54 & 7.35 & 1.64 & 180 & 107 & 0.59 & -0.21 & 0 \\
\hline 810 & 23 & 4.80 & 1.07 & 118 & 51 & 0.43 & -0.56 & 0 \\
\hline 820 & 92 & 9.59 & 2.14 & 236 & 255 & 1.08 & 0.87 & 0 \\
\hline 830 & 1 & 1.00 & 0.22 & 25 & 3 & 0.12 & -1.24 & Yes \\
\hline 880 & 1 & 1.00 & 0.22 & 25 & 7 & 0.29 & -0.88 & 0 \\
\hline 900 & 5 & 2.24 & 0.50 & 55 & 18 & 0.33 & -0.79 & 0 \\
\hline 910 & 188 & 13.71 & 3.06 & 337 & 509 & 1.51 & 1.81 & Yes \\
\hline 920 & 158 & 12.57 & 2.81 & 309 & 425 & 1.38 & 1.52 & Yes \\
\hline 930 & 15 & 3.87 & 0.86 & 95 & 21 & 0.22 & -1.02 & Yes \\
\hline 940 & 96 & 9.80 & 2.19 & 241 & 196 & 0.81 & 0.28 & 0 \\
\hline 950 & 17 & 4.12 & 0.92 & 101 & 34 & 0.34 & -0.77 & 0 \\
\hline 960 & 6 & 2.45 & 0.55 & 60 & 13 & 0.22 & -1.03 & Yes \\
\hline 970 & 162 & 12.73 & 2.84 & 313 & 414 & 1.32 & 1.40 & Yes \\
\hline 980 & 2 & 1.41 & 0.32 & 35 & 4 & 0.12 & -1.26 & Yes \\
\hline $\begin{array}{c}990 \\
(n=57)\end{array}$ & 2 & 1.41 & 0.32 & 35 & 5 & 0.14 & -1.19 & Yes \\
\hline TOTAL & 5126 & 448.02 & 100.01 & 11001 & 10731 & & & 16 \\
\hline mean & & & & & & 0.69 & & \\
\hline sd & & & & & & 0.45 & & \\
\hline $\min$ & & & & & & 0.12 & & \\
\hline $\max$ & & & & & & 1.86 & & \\
\hline
\end{tabular}


Branch L. This is the largest branch with nearly 17,000 adult non-fiction items in its collection and an annual circulation for this section of 9,455. Ten classes out of 61 were $\geq+1 \mathrm{SD}$, and eight were $\leq-1 \mathrm{SD}$. The mean and SD for the C/D Ratio were .72 and .45 respectively, nearly identical to Branch $R$. The range fell between .19 and 1.94 .

Branch N. Although this is the smallest branch in terms of space, total number of holdings and annual circulation, its adult non-fiction collection is slightly larger than Branch $\mathrm{R}$ both in terms of number of loans and items. Current number of adult non-fiction items is nearly 11,000 , and total annual loans for this section was 5,126. For the C/D Ratio the mean of .69 is somewhat lower than for the other two branches, but the SD of .45 repeats or nearly repeats the findings for the other two branches. Out of 57 classes, nine were $\geq+1 \mathrm{SD}$, and seven were $\leq-1 \mathrm{SD}$. C/D Ratios fell between .12 and 1.86 .

\section{Composite Analysis of C/D Ratios}

A comparison of the collections of the three branches reveals some interesting patterns as shown in Table 4. Not only were the SD and number of categories exceeding the threshold nearly identical, but frequently the same categories exceeded the threshold in the same direction. Twenty-six classes out of a total of 62 were found to be over or underrepresented for all branches. In every case, even where only one branch actually exceeded the threshold, all branches repeated the same positive or negative pattern. For most of these categories (20), two or more branches exceeded the threshold. 
TABLE 4

COMPOSITE C/D RATIO ANALYSIS

\begin{tabular}{ll||ll}
\hline \hline Class & $\begin{array}{l}\text { Branches } \\
\pm 1 \text { SD }\end{array}$ & Class & $\begin{array}{l}\text { Branches } \\
\pm 1 \text { SD }\end{array}$ \\
\hline 000 & ++ & 790 & +++ \\
100 & ++ & 820 & + \\
300 & + & 830 & -- \\
360 & ++ & 850 & - \\
530 & - & 860 & - \\
540 & -- & 880 & -- \\
560 & --- & 910 & +++ \\
600 & + & 920 & +++ \\
610 & +++ & 930 & - \\
630 & ++ & 960 & -- \\
640 & +++ & 970 & + \\
670 & -- & 980 & -- \\
740 & ++ & 990 & -- \\
\hline
\end{tabular}

\section{ILL/Holdings Ratio}

The results of the analysis ror Branch $R$ are presented in Table 5. This was the only Branch that kept a record of items it borrowed by Dewey number. The total number of adult non-fiction items borrowed was 189 in 34 classes of the collection. Although the number in each class is small, these loans account for four percent of the non-fiction circulation. The percentage of ILLs for each category was found and compared to the percentage of the collection for each category to produce the ILL/Holdings Ratio. $\mathrm{Z}$ Scores were then calculated for these ratios. The mean ILL/Holdings Ratio is 1.39 and the SD is .84 . Three of the classes were $\geq+1 \mathrm{SD}$, the 320 's, 780's, and 960 's--which indicates that there is an unusually high amount of outside borrowing in these subject areas relative to the size of the collection. Four other categories, the 630's, 740's, 820's, and 910's, were $\leq-1 \mathrm{SD}$ and had unusually 
low ILL activity relative to the size of the collection in these areas. For many categories, however, there was no ILL activity. For these areas ILL data cannot provide additional indications of collection strengths or weaknesses; decisions can be guided only by the previous analysis based on circulation. In addition overall ILL activity for this Branch is low and may not provide the numbers needed to make this as useful a measure as the others.

TABLE 5

ILL Compared to Holdings by Class (Branch R)

\begin{tabular}{l|rrrrrr}
\hline CLASS & No. & \% ILL & \% Holds. & Ratio & Z Scores & \pm 1 \\
\hline & & & & & & \\
\hline 000 & 7 & 3.70 & 2.57 & 1.44 & 0.06 & yes \\
100 & 11 & 5.82 & 3.98 & 1.46 & 0.09 & 0 \\
200 & 10 & 5.29 & 2.47 & 2.14 & 0.90 & 0 \\
300 & 4 & 2.12 & 2.71 & 0.78 & -0.73 & 0 \\
320 & 6 & 3.17 & 1.12 & 2.83 & 1.72 & yes \\
330 & 9 & 4.76 & 2.50 & 1.90 & 0.61 & 0 \\
350 & 2 & 1.06 & 1.31 & 0.81 & -0.69 & 0 \\
360 & 18 & 9.52 & 4.69 & 2.03 & 0.76 & 0 \\
380 & 2 & 1.06 & 0.51 & 2.07 & 0.82 & 0 \\
390 & 3 & 1.59 & 1.07 & 1.48 & 0.11 & 0 \\
510 & 1 & 0.53 & 0.68 & 0.78 & -0.73 & 0 \\
520 & 2 & 1.06 & 0.53 & 2.00 & 0.72 & 0 \\
570 & 3 & 1.59 & 1.01 & 1.57 & 0.22 & 0 \\
610 & 21 & 11.11 & 7.79 & 1.43 & 0.04 & 0 \\
620 & 3 & 1.59 & 2.00 & 0.79 & -0.71 & 0 \\
630 & 2 & 1.06 & 4.32 & 0.24 & -1.36 & yes \\
640 & 11 & 5.82 & 6.19 & 0.94 & -0.54 & 0 \\
650 & 4 & 2.12 & 3.08 & 0.69 & -0.84 & 0 \\
680 & 2 & 1.06 & 1.36 & 0.78 & -0.73 & 0 \\
700 & 1 & 0.53 & 0.52 & 1.02 & -0.44 & 0 \\
730 & 2 & 1.06 & 0.76 & 1.39 & 0.00 & 0
\end{tabular}


TABLE 5--continued

\begin{tabular}{|c|c|c|c|c|c|c|}
\hline CLASS & No. & $\%$ ILL & \% Holds. & Ratio & Z Scores & $\pm 1 S D$ \\
\hline 740 & 1 & 0.53 & 4.08 & 0.13 & -1.50 & 0 \\
\hline 780 & 7 & 3.70 & 1.55 & 2.39 & 1.19 & yes \\
\hline 790 & 23 & 12.17 & 6.10 & 1.99 & 0.72 & 0 \\
\hline 800 & 3 & 1.59 & 1.45 & 1.09 & -0.35 & 0 \\
\hline 810 & 1 & 0.53 & 0.63 & 0.84 & -0.65 & 0 \\
\hline 820 & 4 & 2.12 & 3.84 & 0.55 & -1.00 & yes \\
\hline 890 & 1 & 0.53 & 0.26 & 2.04 & 0.77 & 0 \\
\hline 910 & 3 & 1.59 & 4.89 & 0.32 & -1.27 & yes \\
\hline 920 & 8 & 4.23 & 7.33 & 0.58 & -0.97 & 0 \\
\hline 940 & 4 & 2.12 & 2.16 & 0.98 & -0.49 & yes \\
\hline 950 & 2 & 1.06 & 0.52 & 2.04 & 0.77 & 0 \\
\hline 960 & 1 & 0.53 & 0.12 & 4.41 & 3.59 & yes \\
\hline 970 & 7 & 3.70 & 2.51 & 1.48 & 0.10 & 0 \\
\hline$(n=34)$ & & & & & & \\
\hline TOTAL & 189 & 100.00 & 86.61 & & & 7 \\
\hline MEAN & & & & 1.39 & & \\
\hline SD & & & & 0.84 & & \\
\hline MIN & & & & 0.13 & & \\
\hline MAX & & & & 4.41 & & \\
\hline
\end{tabular}

\section{Selection/Acquisitions Analysis}

Tables 6-8 show the relationship of use to selections and acquisitions for each Branch. If there were no difference between percentage of selections or acquisitions and percentage of loans, the SLB and ALB would be zero. Any differences greater than one are noted in the last two columns.

A comparison of the results reveals that fewer classes exceeded the \pm 1 threshold for the SLB than for the ALB for two out of the three Branches. For Branch N, there were 21 classes exceeding the threshold for the SLB compared to 
22 for the ALB, and Branch L had a corresponding 21 and 24 classes over the threshold. The exception was Branch $\mathrm{R}$ where the results were reversed. There were 20 classes exceeding the threshold for the SLB compared to only 11 for the ALB. These results do not support the assumption made at the start of this study, namely, that fewer subject categories would exceed the threshold for acquisitions than for selections. This assumption was based on the fact that public service personnel were making the acquisition decisions, and non-branch, non-public service staff were making most of the selections. Such measures, however, cannot assess the relevance of selected titles to the needs of branches; it can only indicate whether selections or acquisitions are relatively strong or weak for a particular subject area compared to use at each Branch.

\section{Composite Analysis of SLB and ALB}

Selection and acquisition patterns for the three branches were not as uniform as those found for their collections, but some patterns do emerge when a comparison is made (Table 9). It is quickly evident that either selections or acquisitions in nearly all of the social science categories, the 300 's, exceed the +1 threshold. Over selecting or over purchasing for these categories compared to use appears to be a common error. One factor influencing these decisions could be that the materials in these subject categories are relatively inexpensive. The one exception is in the 390 class, Customs and Folklore, where under selection is the rule for all branches. The 500 divisions, representing Mathematics and Science, exhibit the reverse pattern where categories are frequently under purchased and/or under selected relative to use. In this case, the one exception is the general science category, the 500 's, where over selection occurred. Many of the 600 divisions, the applied 
Table 6.--Selection/Acquisitions Compared to Loans (Branch R)

\begin{tabular}{|c|c|c|c|c|c|c|c|}
\hline CLASS & $\begin{array}{c}\% \\
\text { Loaned }\end{array}$ & $\begin{array}{c}\% \\
\text { Selects. }\end{array}$ & $\begin{array}{c}\% \\
\text { Acquis. }\end{array}$ & $\begin{array}{l}\text { Selects. } \\
\text {-Loans }\end{array}$ & $\begin{array}{l}\text { Acquis. } \\
\text {-Loans }\end{array}$ & $\begin{array}{r}\text { SLB } \\
\pm 1 \\
\end{array}$ & $\begin{array}{l}\text { ALB } \\
\pm 1 \\
\end{array}$ \\
\hline 000 & 2.17 & 3.12 & 2.43 & 0.95 & 0.26 & 0 & 0 \\
\hline 100 & 3.13 & 4.99 & 4.01 & 1.87 & 0.89 & Yes & 0 \\
\hline 200 & 2.36 & 3.00 & 2.55 & 0.64 & 0.20 & 0 & 0 \\
\hline 300 & 2.59 & 4.56 & 2.80 & 1.97 & 0.20 & Yes & 0 \\
\hline 320 & 1.48 & 4.25 & 1.82 & 2.77 & 0.35 & Yes & 0 \\
\hline 330 & 2.25 & 3.12 & 3.77 & 0.87 & 1.52 & 0 & Yes \\
\hline 340 & 2.36 & 2.14 & 4.14 & -0.22 & 1.78 & 0 & Yes \\
\hline 350 & 1.76 & 1.05 & 3.16 & -0.70 & 1.41 & 0 & Yes \\
\hline 360 & 3.30 & 3.90 & 9.25 & 0.60 & 5.95 & 0 & Yes \\
\hline 370 & 2.13 & 1.52 & 2.80 & -0.61 & 0.66 & 0 & 0 \\
\hline 380 & 0.95 & 0.58 & 0.49 & -0.37 & -0.47 & 0 & 0 \\
\hline 390 & 1.67 & 0.47 & 1.09 & -1.20 & -0.57 & Yes & 0 \\
\hline 400 & 1.73 & 0.74 & 1.70 & -0.99 & -0.02 & 0 & 0 \\
\hline 500 & 1.12 & 2.18 & 1.58 & 1.06 & 0.46 & Yes & 0 \\
\hline 510 & 1.31 & 0.16 & 1.34 & -1.16 & 0.03 & Yes & 0 \\
\hline 520 & 1.08 & 0.62 & 0.73 & -0.46 & -0.35 & 0 & 0 \\
\hline 530 & 0.84 & 0.35 & 0.49 & -0.49 & -0.36 & 0 & 0 \\
\hline 540 & 0.67 & 0.04 & 0.12 & -0.64 & -0.55 & 0 & 0 \\
\hline 550 & 1.53 & 0.19 & 0.24 & -1.33 & -1.28 & Yes & Yes \\
\hline 560 & 0.71 & 0.08 & 0.12 & -0.63 & -0.59 & 0 & 0 \\
\hline 570 & 1.39 & 0.43 & 0.61 & -0.96 & -0.78 & 0 & 0 \\
\hline 580 & 0.78 & 0.16 & 0.12 & -0.62 & -0.66 & 0 & 0 \\
\hline 590 & 2.04 & 0.66 & 1.09 & -1.37 & -0.94 & Yes & 0 \\
\hline 600 & 0.64 & 0.08 & 0.12 & -0.56 & -0.51 & 0 & 0 \\
\hline 610 & 4.65 & 6.39 & 7.91 & 1.74 & 3.25 & Yes & Yes \\
\hline 620 & 2.28 & 1.72 & 3.53 & -0.57 & 1.24 & 0 & Yes \\
\hline 630 & 3.79 & 1.68 & 4.14 & -2.11 & 0.35 & Yes & 0 \\
\hline 640 & 4.05 & 6.00 & 4.99 & 1.95 & 0.94 & Yes & 0 \\
\hline 650 & 2.77 & 2.73 & 4.14 & -0.04 & 1.36 & 0 & Yes \\
\hline 660 & 0.50 & 0.00 & 0.00 & -0.50 & -0.50 & 0 & 0 \\
\hline 670 & 0.71 & 0.00 & 0.00 & -0.71 & -0.71 & 0 & 0 \\
\hline 680 & 1.81 & 0.62 & 0.49 & -1.19 & -1.33 & Yes & Yes \\
\hline 690 & 1.67 & 1.01 & 2.07 & -0.65 & 0.40 & 0 & 0 \\
\hline 700 & 0.90 & 0.86 & 0.61 & -0.04 & -0.29 & 0 & 0 \\
\hline
\end{tabular}


Table 6--continued

\begin{tabular}{|c|c|c|c|c|c|c|c|}
\hline CLASS & $\begin{array}{c}\% \\
\text { Loaned }\end{array}$ & $\begin{array}{c}\% \\
\text { Selects. }\end{array}$ & $\begin{array}{c}\% \\
\text { Acquis. }\end{array}$ & $\begin{array}{l}\text { Selects. } \\
\text {-Loans }\end{array}$ & $\begin{array}{l}\text { Acquis. } \\
\text {-Loans }\end{array}$ & $\begin{array}{r}\text { SLB } \\
\pm 1 \\
\end{array}$ & $\begin{array}{l}\text { ALB } \\
\pm 1 \\
\end{array}$ \\
\hline 710 & 0.84 & 0.19 & 0.24 & -0.65 & -0.60 & 0 & 0 \\
\hline 720 & 1.06 & 0.47 & 0.24 & -0.59 & -0.81 & 0 & 0 \\
\hline 730 & 1.35 & 0.27 & 0.36 & -1.08 & -0.98 & Yes & 0 \\
\hline 740 & 3.09 & 2.14 & 2.31 & -0.95 & -0.78 & 0 & 0 \\
\hline 750 & 0.81 & 0.66 & 0.61 & -0.15 & -0.20 & 0 & 0 \\
\hline 770 & 0.71 & 0.55 & 0.00 & -0.17 & -0.71 & 0 & 0 \\
\hline 780 & 1.92 & 1.87 & 1.46 & -0.05 & -0.46 & 0 & 0 \\
\hline 790 & 3.47 & 7.25 & 3.65 & 3.78 & 0.18 & Yes & 0 \\
\hline 800 & 1.84 & 1.33 & 1.58 & -0.52 & -0.26 & 0 & 0 \\
\hline 810 & 1.12 & 6.00 & 0.97 & 4.88 & -0.15 & Yes & 0 \\
\hline 820 & 2.58 & 1.52 & 1.70 & -1.06 & -0.88 & Yes & 0 \\
\hline 830 & 0.32 & 0.19 & 0.00 & -0.12 & -0.32 & 0 & 0 \\
\hline 840 & 0.50 & 0.23 & 0.12 & -0.27 & -0.38 & 0 & 0 \\
\hline 860 & 0.22 & 0.35 & 0.12 & 0.13 & -0.10 & 0 & 0 \\
\hline 880 & 0.45 & 0.08 & 0.12 & -0.37 & -0.33 & 0 & 0 \\
\hline 890 & 0.55 & 0.39 & 0.36 & -0.16 & -0.19 & 0 & 0 \\
\hline 900 & 0.60 & 0.39 & 0.36 & -0.21 & -0.23 & 0 & 0 \\
\hline 910 & 3.34 & 4.41 & 2.07 & 1.06 & -1.28 & Yes & Yes \\
\hline 920 & 3.65 & 0.51 & 2.19 & -3.14 & -1.46 & Yes & Yes \\
\hline 930 & 1.08 & 0.19 & 0.24 & -0.88 & -0.84 & 0 & 0 \\
\hline 940 & 2.42 & 3.94 & 1.95 & 1.51 & -0.48 & Yes & 0 \\
\hline 950 & 1.17 & 1.87 & 1.82 & 0.70 & 0.66 & 0 & 0 \\
\hline 960 & 0.45 & 0.35 & 0.36 & -0.10 & -0.08 & 0 & 0 \\
\hline 970 & 2.55 & 4.95 & 2.43 & 2.41 & -0.11 & Yes & 0 \\
\hline 980 & 0.45 & 0.23 & 0.24 & -0.22 & -0.21 & 0 & 0 \\
\hline 990 & 0.32 & 0.19 & 0.00 & -0.12 & -0.32 & 0 & 0 \\
\hline TOTAL & 100.00 & 99.96 & 100.00 & -0.04 & 0.00 & 20 & \\
\hline MIN & & & & -3.14 & -1.46 & & \\
\hline MAX & & & & 4.88 & 5.95 & & \\
\hline RANGE & & & & 8.02 & 7.41 & & \\
\hline
\end{tabular}


Table 7.--Selection/Acquisitions Compared to Loans (Branch L)

\begin{tabular}{l|rrrrrrr}
\hline & $\begin{array}{r}\% \\
\text { CLASS }\end{array}$ & Loaned & Selects. & Acquis. & -Loans & $\begin{array}{r}\text { Acquis. } \\
\text {-Loans }\end{array}$ & $\begin{array}{r}\text { SLB } \\
\pm 1\end{array}$ \\
\hline & & & ALB \\
\hline 00 & 2.53 & 3.12 & 3.76 & 0.59 & 1.23 & 0 & Yes \\
100 & 2.99 & 4.99 & 1.57 & 2.00 & -1.42 & Yes & Yes \\
200 & 2.65 & 3.00 & 0.47 & 0.35 & -2.18 & 0 & Yes \\
300 & 2.75 & 4.56 & 2.35 & 1.82 & -0.39 & Yes & 0 \\
320 & 1.72 & 4.25 & 1.10 & 2.53 & -0.62 & Yes & 0 \\
330 & 2.36 & 3.12 & 2.82 & 0.75 & 0.46 & 0 & 0 \\
340 & 2.05 & 2.14 & 8.62 & 0.09 & 6.57 & 0 & Yes \\
350 & 1.46 & 1.05 & 1.10 & -0.41 & -0.37 & 0 & 0 \\
360 & 3.15 & 3.90 & 5.96 & 0.75 & 2.81 & 0 & Yes \\
370 & 2.12 & 1.52 & 3.13 & -0.60 & 1.02 & 0 & Yes \\
380 & 1.13 & 0.58 & 0.47 & -0.55 & -0.66 & 0 & 0 \\
390 & 1.68 & 0.47 & 1.10 & -1.21 & -0.58 & Yes & 0 \\
400 & 1.62 & 0.74 & 1.41 & -0.88 & -0.21 & 0 & 0 \\
500 & 0.85 & 2.18 & 1.88 & 1.34 & 1.04 & Yes & Yes \\
510 & 1.05 & 0.16 & 0.47 & -0.90 & -0.58 & 0 & 0 \\
520 & 1.35 & 0.62 & 0.16 & -0.73 & -1.19 & 0 & Yes \\
530 & 0.57 & 0.35 & 0.78 & -0.22 & 0.22 & 0 & 0 \\
540 & 0.50 & 0.04 & 0.16 & -0.46 & -0.34 & 0 & 0 \\
550 & 1.24 & 0.19 & 0.16 & -1.04 & -1.08 & Yes & Yes \\
560 & 0.67 & 0.08 & 0.16 & -0.59 & -0.51 & 0 & 0 \\
570 & 1.62 & 0.43 & 0.78 & -1.19 & -0.83 & Yes & 0 \\
580 & 1.20 & 0.16 & 0.00 & -1.04 & -1.20 & Yes & Yes \\
590 & 1.98 & 0.66 & 1.25 & -1.32 & -0.73 & Yes & 0 \\
600 & 0.57 & 0.08 & 0.31 & -0.49 & -0.25 & 0 & 0 \\
610 & 4.55 & 6.39 & 13.17 & 1.85 & 8.62 & Yes & Yes \\
620 & 1.94 & 1.72 & 2.35 & -0.23 & 0.41 & 0 & 0 \\
630 & 3.28 & 1.68 & 2.82 & -1.60 & -0.46 & Yes & 0 \\
640 & 3.95 & 6.00 & 7.05 & 2.05 & 3.10 & Yes & Yes \\
650 & 2.27 & 2.73 & 3.61 & 0.46 & 1.34 & 0 & Yes \\
660 & 0.47 & 0.00 & 0.00 & -0.47 & -0.47 & 0 & 0 \\
670 & 0.63 & 0.00 & 0.00 & -0.63 & -0.63 & 0 & 0 \\
680 & 1.48 & 0.62 & 0.47 & -0.86 & -1.01 & 0 & Yes \\
690 & 1.57 & 1.01 & 1.72 & -0.56 & 0.15 & 0 & 0 \\
700 & 0.94 & 0.86 & 0.16 & -0.08 & -0.78 & 0 & 0
\end{tabular}


Table 7-continued

\begin{tabular}{|c|c|c|c|c|c|c|c|}
\hline CLASS & $\begin{array}{c}\% \\
\text { Loaned } \\
\end{array}$ & $\begin{array}{c}\% \\
\text { Selects. }\end{array}$ & $\begin{array}{c}\% \\
\text { Acquis. }\end{array}$ & $\begin{array}{l}\text { Selects. } \\
\text {-Loans }\end{array}$ & $\begin{array}{l}\text { Acquis. } \\
\text {-Loans }\end{array}$ & $\begin{array}{r}\text { SLB } \\
\pm 1 \\
\end{array}$ & $\begin{array}{l}\text { ALB } \\
\pm 1 \\
\end{array}$ \\
\hline 710 & 0.90 & 0.19 & 0.47 & -0.71 & -0.43 & 0 & 0 \\
\hline 720 & 1.30 & 0.47 & 0.16 & -0.84 & -1.15 & 0 & Yes \\
\hline 730 & 1.05 & 0.27 & 0.63 & -0.78 & -0.43 & 0 & 0 \\
\hline 740 & 2.89 & 2.14 & 1.88 & -0.74 & -1.00 & 0 & Yes \\
\hline 750 & 0.82 & 0.66 & 0.16 & -0.15 & -0.66 & 0 & 0 \\
\hline 770 & 0.87 & 0.55 & 0.16 & -0.33 & -0.72 & 0 & 0 \\
\hline 780 & 1.85 & 1.87 & 1.10 & 0.02 & -0.75 & 0 & 0 \\
\hline 790 & 3.59 & 7.25 & 4.70 & 3.66 & 1.11 & Yes & Yes \\
\hline 800 & 1.68 & 1.33 & 1.41 & -0.35 & -0.27 & 0 & 0 \\
\hline 810 & 1.46 & 6.00 & 1.25 & 4.54 & -0.21 & Yes & 0 \\
\hline 820 & 3.23 & 1.52 & 1.41 & -1.71 & -1.82 & Yes & Yes \\
\hline 830 & 0.31 & 0.19 & 0.00 & -0.12 & -0.31 & 0 & 0 \\
\hline 840 & 0.57 & 0.23 & 0.16 & -0.33 & -0.41 & 0 & 0 \\
\hline 850 & 0.27 & 0.04 & 0.00 & -0.23 & -0.27 & 0 & 0 \\
\hline 860 & 0.47 & 0.35 & 0.16 & -0.12 & -0.31 & 0 & 0 \\
\hline 880 & 0.54 & 0.08 & 0.16 & -0.47 & -0.39 & 0 & 0 \\
\hline 890 & 0.72 & 0.39 & 0.16 & -0.33 & -0.56 & 0 & 0 \\
\hline 900 & 0.67 & 0.39 & 0.31 & -0.28 & -0.35 & 0 & 0 \\
\hline 910 & 3.75 & 4.41 & 5.96 & 0.66 & 2.21 & 0 & Yes \\
\hline 920 & 3.63 & 0.51 & 2.51 & -3.13 & -1.13 & Yes & Yes \\
\hline 930 & 0.89 & 0.19 & 0.00 & -0.69 & -0.89 & 0 & 0 \\
\hline 940 & 2.36 & 3.94 & 1.25 & 1.58 & -1.11 & Yes & Yes \\
\hline 950 & 1.04 & 1.87 & 0.16 & 0.83 & -0.88 & 0 & 0 \\
\hline 960 & 0.52 & 0.35 & 0.00 & -0.17 & -0.52 & 0 & 0 \\
\hline 970 & 2.82 & 4.95 & 4.55 & 2.13 & 1.73 & Yes & Yes \\
\hline 980 & 0.44 & 0.23 & 0.00 & -0.21 & -0.44 & 0 & 0 \\
\hline 990 & 0.50 & 0.19 & 0.00 & -0.30 & -0.50 & 0 & 0 \\
\hline TOTAL & 99.50 & 100.00 & 100.00 & 0.00 & 0.00 & 18 & 22 \\
\hline MIN & & & & -3.13 & -2.18 & & \\
\hline MAX & & & & 4.54 & 8.62 & & \\
\hline RANGE & & & & 7.67 & 10.80 & & \\
\hline
\end{tabular}


Table 8.--Selection/Acquisitions Compared to Loans (Branch N)

\begin{tabular}{|c|c|c|c|c|c|c|c|}
\hline CLASS & $\begin{array}{c}\% \\
\text { Loaned } \\
\end{array}$ & $\begin{array}{c}\% \\
\text { Selects. } \\
\end{array}$ & $\begin{array}{c}\% \\
\text { Acquis. }\end{array}$ & $\begin{array}{r}\text { Selects. } \\
\text {-Loans }\end{array}$ & $\begin{array}{l}\text { Acquis. } \\
\text {-Loans }\end{array}$ & $\begin{array}{c}\text { SLB } \\
\pm 1 \\
\end{array}$ & $\begin{array}{l}\text { ALB } \\
\pm 1 \\
\end{array}$ \\
\hline 000 & 2.62 & 3.12 & 1.35 & 0.50 & -1.27 & 0 & Yes \\
\hline 100 & 3.44 & 4.99 & 2.25 & 1.55 & -1.19 & Yes & Yes \\
\hline 200 & 2.05 & 3.00 & 0.68 & 0.96 & -1.37 & 0 & Yes \\
\hline 300 & 2.09 & 4.56 & 2.48 & 2.47 & 0.38 & Yes & 0 \\
\hline 320 & 1.38 & 4.25 & 0.23 & 2.87 & -1.15 & Yes & Yes \\
\hline 330 & 2.35 & 3.12 & 5.63 & 0.77 & 3.28 & 0 & Yes \\
\hline 340 & 2.12 & 2.14 & 6.98 & 0.03 & 4.86 & 0 & Yes \\
\hline 350 & 1.26 & 1.05 & 1.80 & -0.21 & 0.54 & 0 & 0 \\
\hline 360 & 3.16 & 3.90 & 4.50 & 0.74 & 1.35 & 0 & Yes \\
\hline 370 & 2.11 & 1.52 & 2.48 & -0.59 & 0.37 & 0 & 0 \\
\hline 380 & 0.97 & 0.58 & 0.68 & -0.39 & -0.30 & 0 & 0 \\
\hline 390 & 1.59 & 0.47 & 0.68 & -1.13 & -0.92 & Yes & 0 \\
\hline 400 & 1.61 & 0.74 & 1.13 & -0.87 & -0.48 & 0 & 0 \\
\hline 500 & 0.92 & 2.18 & 1.35 & 1.26 & 0.43 & Yes & 0 \\
\hline 510 & 1.28 & 0.16 & 0.23 & -1.13 & -1.06 & Yes & Yes \\
\hline 520 & 1.38 & 0.62 & 0.00 & -0.75 & -1.38 & 0 & Yes \\
\hline 530 & 0.67 & 0.35 & 0.23 & -0.32 & -0.44 & 0 & 0 \\
\hline 540 & 0.22 & 0.04 & 0.00 & -0.18 & -0.22 & 0 & 0 \\
\hline 550 & 1.39 & 0.19 & 0.23 & -1.20 & -1.17 & Yes & Yes \\
\hline 560 & 0.74 & 0.08 & 0.00 & -0.66 & -0.74 & 0 & 0 \\
\hline 570 & 1.36 & 0.43 & 0.23 & -0.93 & -1.13 & 0 & Yes \\
\hline 580 & 0.84 & 0.16 & 0.00 & -0.68 & -0.84 & 0 & 0 \\
\hline 590 & 2.38 & 0.66 & 0.68 & -1.72 & -1.71 & Yes & Yes \\
\hline 600 & 0.92 & 0.08 & 0.23 & -0.84 & -0.70 & 0 & 0 \\
\hline 610 & 4.45 & 6.39 & 10.81 & 1.95 & 6.36 & Yes & Yes \\
\hline 620 & 2.35 & 1.72 & 4.28 & -0.64 & 1.93 & 0 & Yes \\
\hline 630 & 5.57 & 1.68 & 5.63 & -3.89 & 0.06 & Yes & 0 \\
\hline 640 & 4.34 & 6.00 & 8.78 & 1.66 & 4.44 & Yes & Yes \\
\hline 650 & 3.04 & 2.73 & 5.63 & -0.31 & 2.59 & 0 & Yes \\
\hline 660 & 0.59 & 0.00 & 0.00 & -0.59 & -0.59 & 0 & 0 \\
\hline 670 & 0.63 & 0.00 & 0.00 & -0.63 & -0.63 & 0 & 0 \\
\hline 680 & 1.77 & 0.62 & 1.58 & -1.15 & -0.20 & Yes & 0 \\
\hline 690 & 1.96 & 1.01 & 3.15 & -0.95 & 1.19 & 0 & Yes \\
\hline 700 & 0.86 & 0.86 & 0.23 & -0.01 & -0.64 & 0 & 0 \\
\hline
\end{tabular}


Table 8--continued

\begin{tabular}{|c|c|c|c|c|c|c|c|}
\hline CLASS & $\begin{array}{c}\% \\
\text { Loaned } \\
\end{array}$ & $\begin{array}{c}\% \\
\text { Selects. }\end{array}$ & $\begin{array}{c}\% \\
\text { Acquis. }\end{array}$ & $\begin{array}{l}\text { Selects. } \\
\text {-Loans }\end{array}$ & $\begin{array}{l}\text { Acquis. } \\
\text {-Loans }\end{array}$ & $\begin{array}{c}\text { SLB } \\
\pm 1 \\
\end{array}$ & $\begin{array}{l}\text { ALB } \\
\pm 1 \\
\end{array}$ \\
\hline 710 & 1.20 & 0.19 & 0.90 & -1.01 & -0.30 & Yes & 0 \\
\hline 720 & 1.55 & 0.47 & 0.90 & -1.08 & -0.65 & Yes & 0 \\
\hline 730 & 1.16 & 0.27 & 0.68 & -0.89 & -0.48 & 0 & 0 \\
\hline 740 & 3.65 & 2.14 & 2.93 & -1.51 & -0.73 & Yes & 0 \\
\hline 750 & 0.80 & 0.66 & 0.90 & -0.14 & 0.10 & 0 & 0 \\
\hline 770 & 1.22 & 0.55 & 0.00 & -0.68 & -1.22 & 0 & Yes \\
\hline 780 & 1.93 & 1.87 & 1.58 & -0.06 & -0.36 & 0 & 0 \\
\hline 790 & 4.41 & 7.25 & 6.53 & 2.84 & 2.12 & Yes & Yes \\
\hline 800 & 1.64 & 1.33 & 0.90 & -0.31 & -0.74 & 0 & 0 \\
\hline 810 & 1.07 & 6.00 & 0.00 & 4.93 & -1.07 & Yes & Yes \\
\hline 820 & 2.14 & 1.52 & 0.23 & -0.62 & -1.92 & 0 & Yes \\
\hline 830 & 0.22 & 0.19 & 0.00 & -0.03 & -0.22 & 0 & 0 \\
\hline 880 & 0.22 & 0.08 & 0.00 & -0.15 & -0.22 & 0 & 0 \\
\hline 900 & 0.50 & 0.39 & 0.00 & -0.11 & -0.50 & 0 & 0 \\
\hline 910 & 3.06 & 4.41 & 4.28 & 1.34 & 1.22 & Yes & Yes \\
\hline 920 & 2.81 & 0.51 & 1.58 & -2.30 & -1.23 & Yes & Yes \\
\hline 930 & 0.86 & 0.19 & 0.00 & -0.67 & -0.86 & 0 & 0 \\
\hline 940 & 2.19 & 3.94 & 0.23 & 1.75 & -1.96 & Yes & Yes \\
\hline 950 & 0.92 & 1.87 & 0.23 & 0.95 & -0.70 & 0 & 0 \\
\hline 960 & 0.55 & 0.35 & 0.23 & -0.20 & -0.32 & 0 & 0 \\
\hline 970 & 2.84 & 4.95 & 3.83 & 2.11 & 0.99 & Yes & 0 \\
\hline 980 & 0.32 & 0.23 & 0.00 & -0.08 & -0.32 & 0 & 0 \\
\hline 990 & 0.32 & 0.19 & 0.00 & -0.12 & -0.32 & 0 & 0 \\
\hline TOTAL & 100.01 & 98.99 & 100 & -1.02 & -0.01 & 21 & 24 \\
\hline MIN & & & & -3.89 & -1.96 & & \\
\hline $\operatorname{MAX}$ & & & & 4.93 & 6.36 & & \\
\hline RANGE & & & & 8.82 & 8.33 & & \\
\hline
\end{tabular}


TABLE 9

COMPOSITE SLB AND ALB ANALYSIS

\begin{tabular}{|c|c|c|c|c|c|}
\hline Class & $\begin{array}{l}\text { Branches } \\
\pm 1 \mathrm{SLB}\end{array}$ & $\begin{array}{l}\text { Branches } \\
\pm 1 \text { ALB }\end{array}$ & Class & $\begin{array}{l}\text { Branches } \\
\pm 1 \mathrm{SLB}\end{array}$ & $\begin{array}{l}\text { Branches } \\
\pm 1 \text { ALB }\end{array}$ \\
\hline 000 & \multirow{3}{*}{+++} & +- & 670 & \multirow{4}{*}{--} & \\
\hline 100 & & - & 680 & & -- \\
\hline 200 & & - & \multirow{2}{*}{700} & & \multirow[t]{2}{*}{+} \\
\hline 300 & \multicolumn{2}{|l|}{+++} & & & \\
\hline 320 & \multirow[t]{6}{*}{+++} & - & 710 & - & + \\
\hline 330 & & $+t$ & 720 & - & \multirow[t]{2}{*}{-} \\
\hline 340 & & $t+t$ & 730 & - & \\
\hline 350 & & + & 740 & - & - \\
\hline 360 & & $+t+$ & 750 & & \\
\hline $\begin{array}{l}370 \\
380\end{array}$ & & + & $\begin{array}{l}770 \\
780\end{array}$ & & - \\
\hline $\begin{array}{l}390 \\
400\end{array}$ & $\cdots$ & & $\begin{array}{l}790 \\
800\end{array}$ & +++ & ++ \\
\hline 500 & \multicolumn{2}{|l|}{$+t+$} & 810 & \multirow{8}{*}{$\begin{array}{l}++ \\
-\end{array}$} & \multirow{2}{*}{-} \\
\hline 510 & & - & 820 & & \\
\hline 520 & & -- & 830 & & \multirow{6}{*}{-} \\
\hline $\begin{array}{l}530 \\
540\end{array}$ & & & $\begin{array}{l}840 \\
850\end{array}$ & & \\
\hline 550 & \multirow[t]{2}{*}{--} & \multirow[t]{2}{*}{--} & $\begin{array}{l}850 \\
860\end{array}$ & & \\
\hline 560 & & & 880 & & \\
\hline 570 & - & - & 390 & & \\
\hline 580 & - & - & 900 & & \\
\hline 590 & $\cdots$ & - & 910 & ++ & $+t-$ \\
\hline 600 & & & 920 & $\ldots$ & $\ldots$ \\
\hline 610 & $+t+$ & $+t+$ & 930 & & \\
\hline 620 & & $t+$ & 940 & $++t$ & - \\
\hline 630 & $++t$ & & 950 & & \\
\hline 640 & +++ & ++ & 960 & & \\
\hline 650 & & +++ & 970 & $+t+$ & + \\
\hline 660 & & & $\begin{array}{l}980 \\
990\end{array}$ & & \\
\hline
\end{tabular}

science or technology classes, show the same trend as the social sciences, where over selection and purchasing are frequently demonstrated. This same tendency is revealed in a few other classes: the 790's (Sports and Recreation), the 910's (Travel), and the 970's (North American History). The 100 and 940 classes show 
over selection to be common, but purchasing is weak compared to use. This may indicate that titles being selected are judged by branch staff to be generally inappropriate for their collections and borrowers.

\section{Collection Profile}

By graphing the results obtained from the above analyses, the status of each branch collection is easily assessed. The ideal profile would be a straight line with all measures lying along 0 on the $\mathrm{Y}$ axis. The $\mathrm{Z}$ Scores for the C/D Ratios and ILL/Holdings Ratios would be 0 , if the Ratio were at the mean for these measures. The Acquisition Loan Balance and Selection Loan Balance would be zero if there were no differences between percentages of use and acquisitions and selections.

Classes 001 through 400 are represented in Figures 1-3 for the three Branches. Figure 1 also includes the additional ILL/Holdings Ratio obtained for Branch R. It is evident from Figure 1 that only the 320 category in this subject range exceeded the +1 SD threshold for the ILL/Holdings Ratio which would suggest that there were high levels of outside borrowing relative to the size of holdings. However, the measures of the collection and acquisitions were near to the ideal levels for this category which would not confirm a conclusion that additional purchasing or weeding is necessarily required. Nevertheless, an examination of the titles requested on interlibrary loan could provide some clues to subjects and titles of interest to the library's users. It is also immediately evident that the 360 category needs additional attention. Both the C/D Ratio and ALB exceed the +1 threshold indirating that this category is both overrepresented in the collection and that acquisitions far exceed the level of use. The 100 class is the only other subject area 


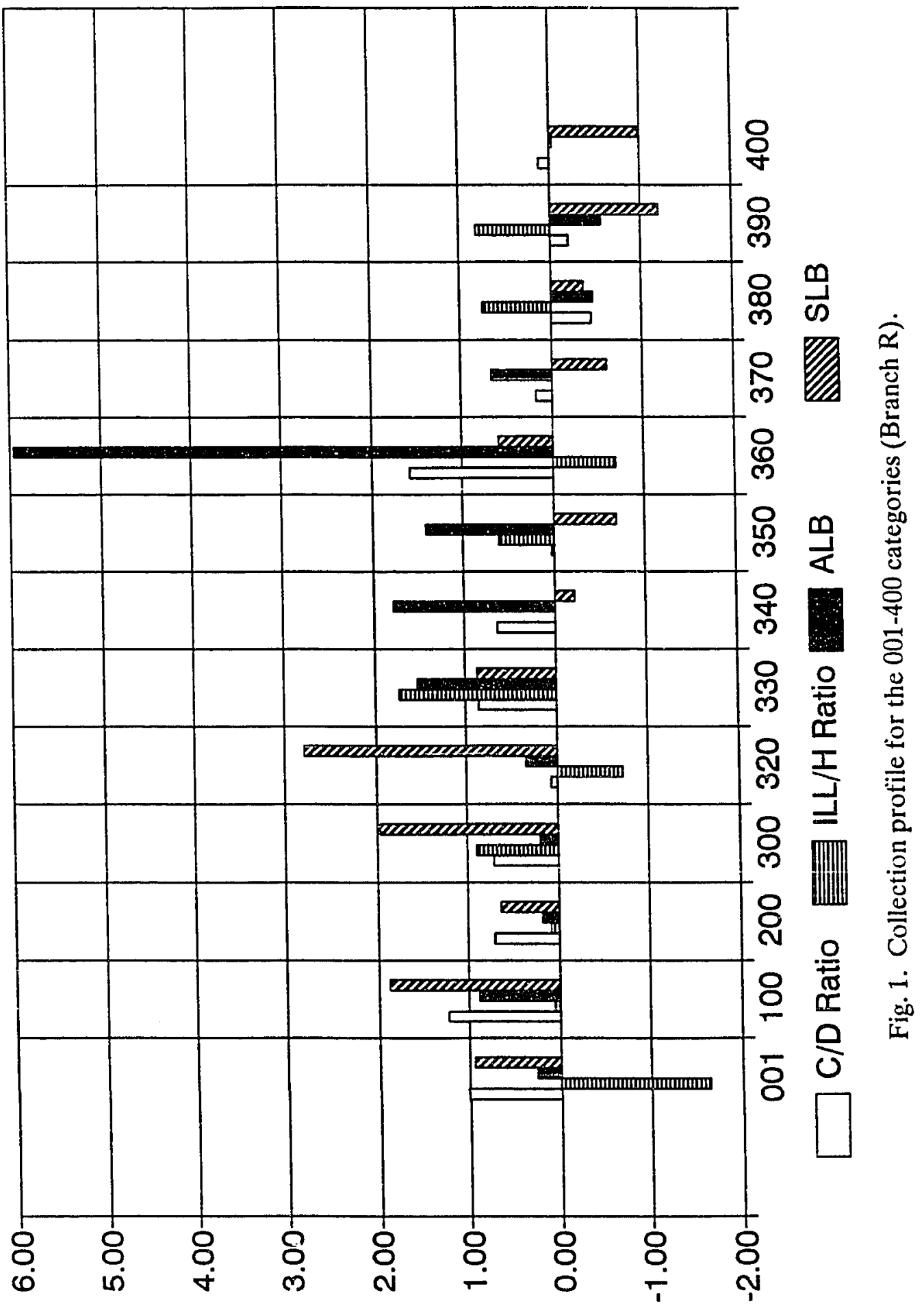




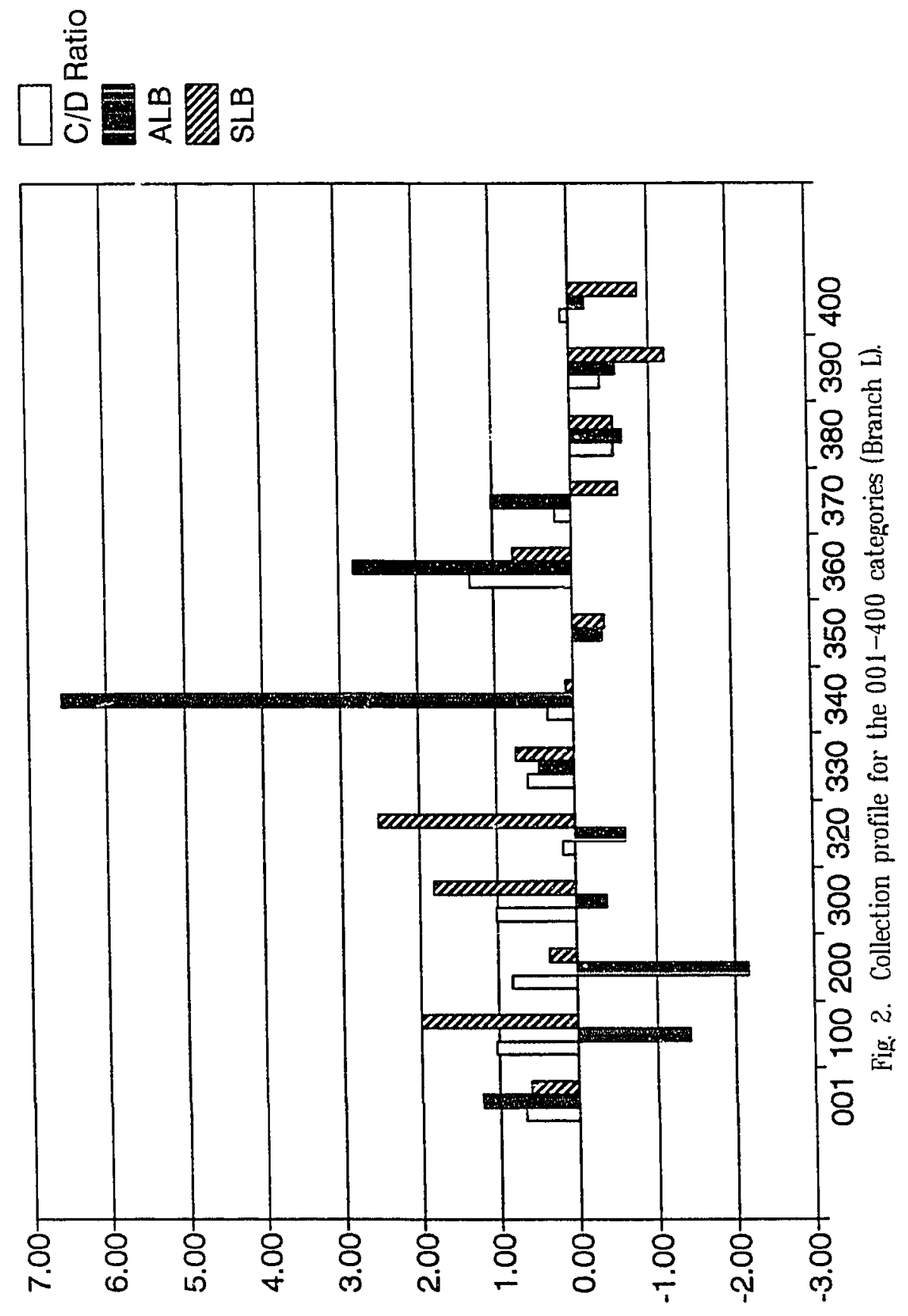



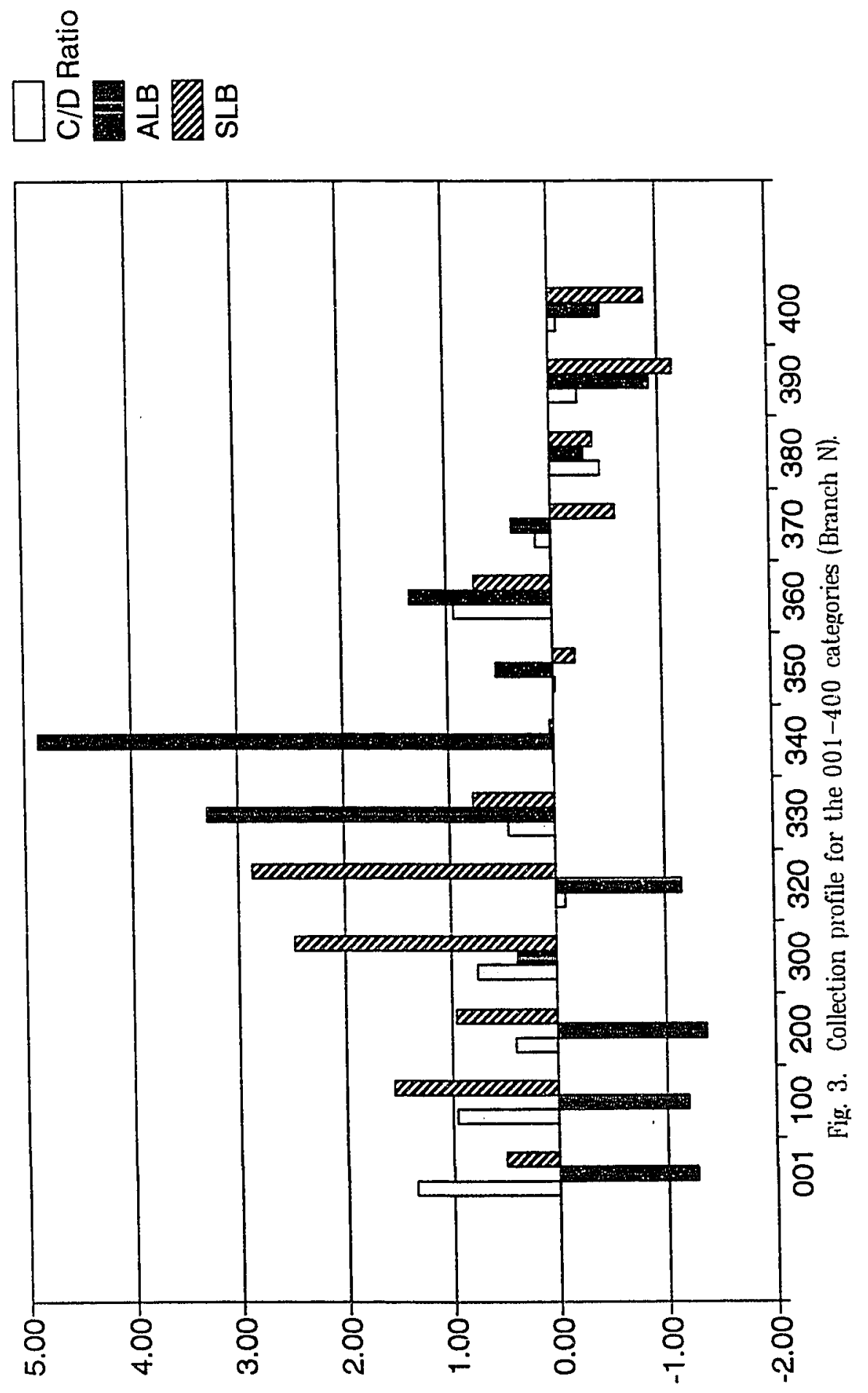
where two measures, the C/D Ratio and SLB, exceeded the threshold. Weeding of this area, and a reduced level of development appears to be needed. Three other categories, the 320,330 and 340 classes, had only one measure, the ALB, which exceeded the threshold. Purchasing levels for these classes should probably be reexamined.

Figure 2 presents the profile of the collection for Branch L. All three measures exceed the threshold for the 100 category: the C/D Ratio is high, the ALB is low, and the SLB is high. This outcome indicates that the collection is overrepresented in this class, and selections are higher than needed, but low acquisitions along with weeding may correct the imbalance. A high SLB and low ALB may also suggest that new titles need to be closely examined for their appropriateness in meeting branch needs. In the 360 class Branch $\mathrm{L}$ has the same problem as Branch $\mathrm{R}$, although not as severe. One other category, the 300 class, has two measures falling outside the acceptable range. Weeding and a decreased level of development is indicated. The 350 class, in contrast, appears to be close to the ideal on all three measures; the C/D Ratio is actually 0.

All three branches are remarkably high for the ALB in the 340 class. When it is noted that the 340 class includes legal subject material, however, the high ALB may be understood, since this is an area that must be constantly updated and weeded. All of the C/D Ratios are well within the acceptable range for these Branches in this area which suggests that outdated items are probably being withdrawn.

The 600 divisions are profiled in Figures 4-6. The remainder of the subject areas are included in Appendix 2. Again it should be noted that although all three branches far exceed the thresholds for the three measures in the 610 class, the 


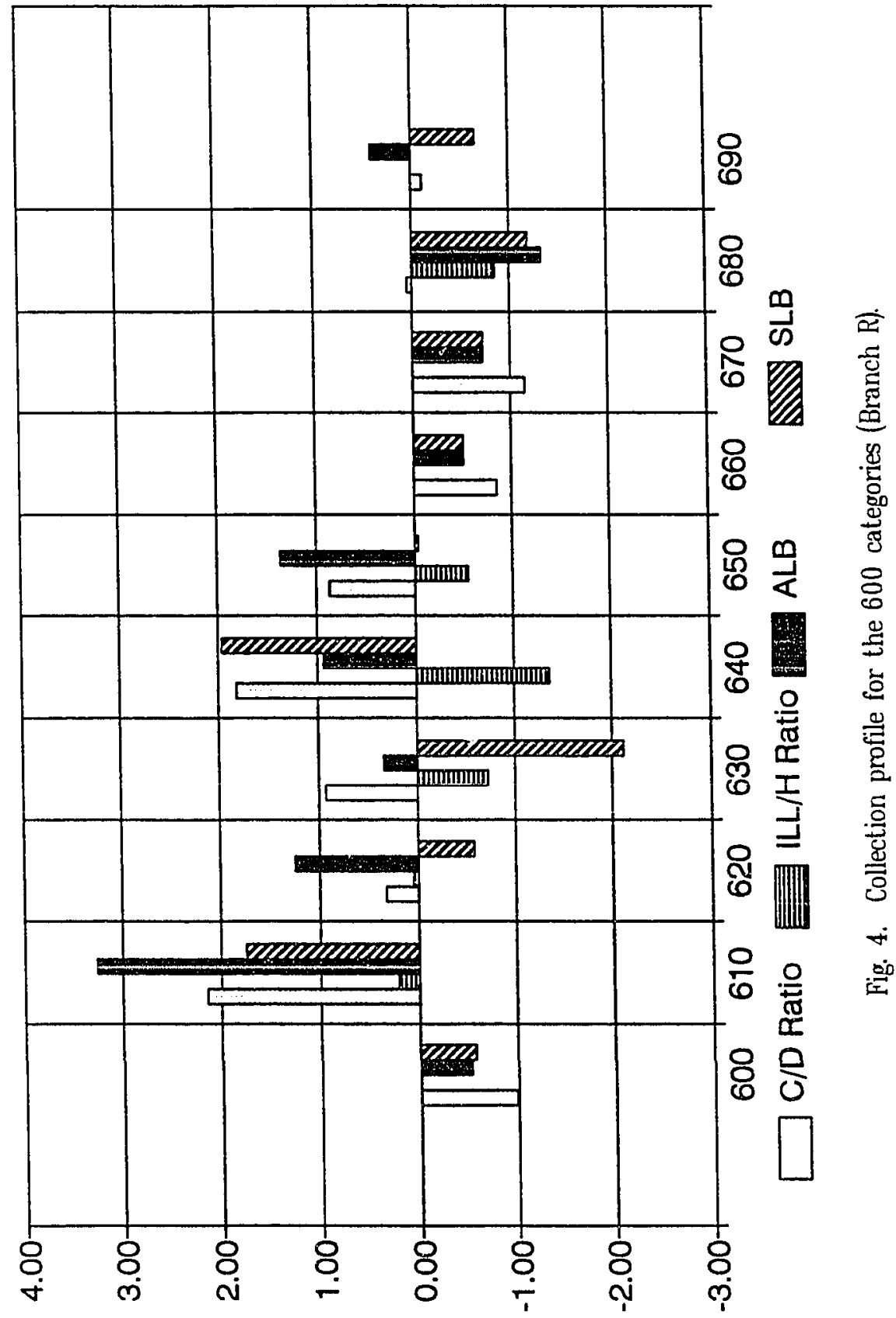




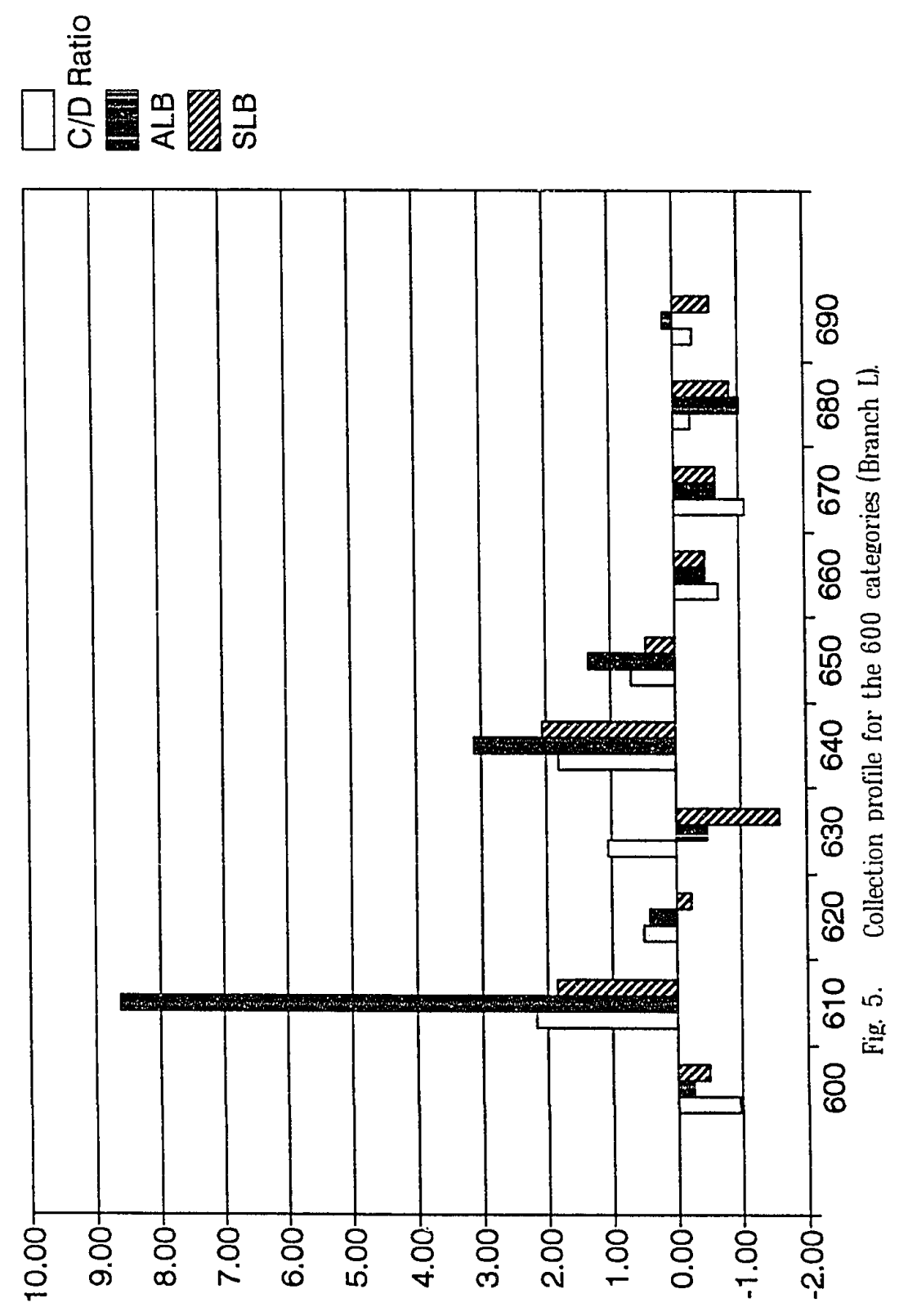




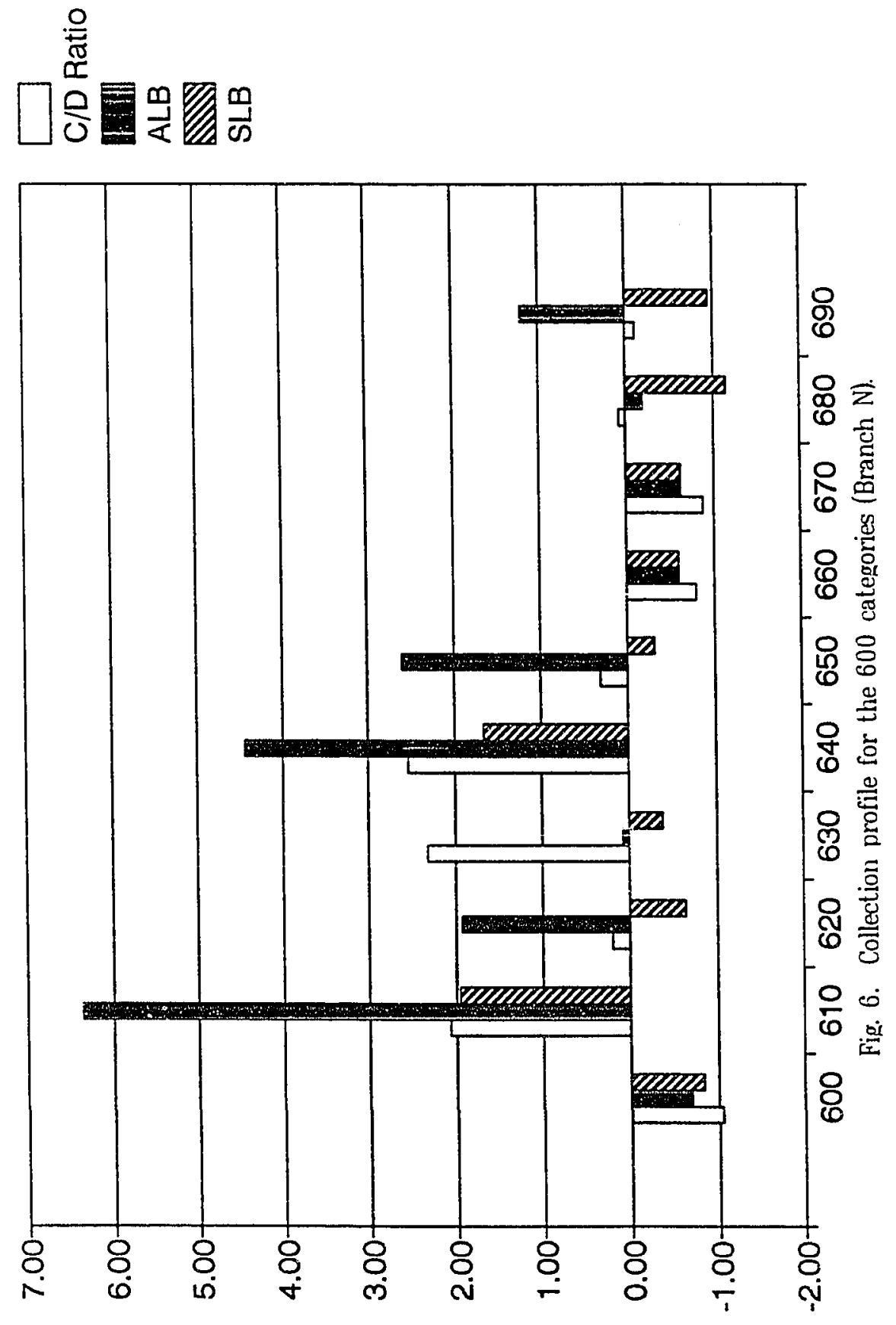


special nature of the subject matter which includes medical information may partially explain this result. The high C/D Ratios indicate, however, that more items should be weeded. Another notable imbalance for all three branches is in the 640 class. For Branches $\mathrm{N}$ and $\mathrm{L}$, all three measures exceed the threshold. The majority of material in this category includes cookbooks. It would seem that no one can resist selecting or buying in this category, much less weeding in this area. 


\section{CHAPTER 5}

\section{CONCLUSION}

The methods developed in this evaluation of small public library collections represent an attempt to advance the use and development of analytical tools and guidelines for making collection management decisions, especially when the shelf capacity or budget for the collection may be changing. One assumption underlying the collection analysis measure adapted for this study is that the relative size of holdings has minimal influence on the circulation in a particular interest category. This assumption may have greater validity in a public library than perhaps in a library in an academic setting. No matter how many cookbooks may be present in a collection, for example, circulation in this category is unlikely to increase relative to other categories if borrowers, for whatever reasons, are disinclined to seek them out. Based on 14 years of informal observation in several public libraries, users of the non-fiction collection generally enter the library with specific, though often vaguely articulated, needs and interests. Browsing and serendipity will always be a factor, however, and, in the case of relatively small categories, where choice is limited, the size of holdings must assume greater significance. Miclellan attempted to compensate for the small numbers in these categories by basing his calculation of desired number of items on square root. The influence on circulation generated by the relative size of a category, though unaccounted for in this analysis, should not be entirely ignored. 
Furthermore, the measures of use for this study were limited to total transactions in a category. A few titles, or even duplicate copies of the same title, therefore, could account for a majority of the loans, although multiple volumes were not frequently found in the collections. The analysis gives only an indication of the relative interest in a subject area and points to categories in need of further attention. When the data becomes available for Dewey divisions, the percentage of titles having at least one circulation in a given time period would be another desirable measure of a collection's use.

Usage should not be the only criterion influencing buying and collection management decisions, but it is and should be a factor for public libraries. The methods developed in this study are based on empirical evidence as compared to the intuitive subjective methods or comparisons of gross circulation percentages for broad materials or collection categories which have been relied on in the past. Additional variables could provide a more refined analysis, particularly for categories in the normal range of representation, such as depreciation analysis or a sampling for publication year to determine the age of the collection by category.

The results of this analysis did not support the expectation that public service staff, based on informal observations of patron behavior and familiarity with branch library users, would make collection buying decisions that would deviate less from usage patterns than selection decisions made by collection development staff. It must be concluded that impressions gained from directly serving library borrowers do not necessarily lead to an increase in the relationship between percentage of use and percentage of acquisitions. Acquisitions largely depend on the relevance to branch needs of titles selected by collection development staff, as judged by branch managers, and the amount of effort given to collection assessment and 
development by these managers. With limited staffing and budgets, these activities are often curtailed in order to meet the demands of directly serving the public. Providing analytical tools and objective criteria to guide collection management efforts and make the time available to spend on collection management more effective and efficient was the major purpose of this study.

The analysis revealed a number of subject divisions to be overrepresented based on a statistical analysis of use and shelf-capacity. Probably in need of even greater attention are the areas found to be underrepresented. The 500 interest categories, which include all the science subject divisions, were found to be frequently underrepresented in branch collections as well as weak in terms of selections and acquisitions compared to use. This result should provide all staff responsible for collection development and management a clear indication for future action. The literature categories ( 800 's) were also found to be frequently underrepresented in collections, but only in the 820 's, English literature, were selections and acquisitions found to be inadequate.

When the findings are compared to interlibrary loan data, an even clearer picture can emerge of the status of the collection upon which to base collection management decisions. However, in a branch library requests for interlibrary loans can be minimal, as in the case of the library used in this study. Various factors could cause this situation, probably one being socioeconomic and another the nearby location of larger libraries. In this case, the usefulness of interlibrary loan analysis may be reduced, and greater reliance must be placed on the analysis based on loans from the local collection.

To determine if selection and buying patterns reflect the needs of the collection and patterns of use, a selection and acquisitions loan balance was calculated. For 
some interest categories, the proportion of titles made available for purchase far exceeded the needs of the branch compared to the proportion of loans. The results also highlighted several other categories where the proportion of orders notably exceeded loans. Nevertheless, keeping critical and fast-changing subject matter upto-date can explain and justify an imbalance between acquisitions and material loaned. The findings for the medical subject division (610) illustrate this special situation.

By using a spreadsheet to calculate and graph the results, a collection profile was produced that quickly identified areas in need of further attention and gave strong indication of the kinds of action required to bring categories of the collection into a normal range of representation.

As automation becomes more sophisticated for public libraries, data for analysis and use in management information systems should become more widely available. Techniques that can be easily and quickly employed and understood by information managers need to be explored and developed. Public libraries no longer operate in a non-competitive environment. Such techniques could help to increase the responsiveness of these library organizations to their community of users and potential users, particularly in the area of collection management in a period when materials budgets are declining and costs for shelf space are increasing. 
APPENDIX 1

DEWEY DECIMAL CLASSIFICATION DIVISIONS 


\begin{tabular}{|c|c|c|c|}
\hline 000 & General Knowledge & $\begin{array}{l}670 \\
680\end{array}$ & $\begin{array}{l}\text { Manufactures } \\
\text { Other Manufactures }\end{array}$ \\
\hline 100 & $\begin{array}{l}\text { Philosophy and } \\
\text { Psychology }\end{array}$ & 690 & Construction \\
\hline 200 & Religion & $\begin{array}{l}700 \\
710 \\
720\end{array}$ & $\begin{array}{l}\text { Arts } \\
\text { Landscape and Civic Art } \\
\text { Architecture }\end{array}$ \\
\hline 300 & Social Science & 730 & Sculpture \\
\hline 310 & Statistics & 740 & Drawing \\
\hline 320 & Political Science & 750 & Painting \\
\hline 330 & Economics & 760 & Prints and Printmaking \\
\hline 340 & Law & 770 & Photography \\
\hline 350 & Local Government & 780 & Music \\
\hline $\begin{array}{l}360 \\
370\end{array}$ & $\begin{array}{l}\text { Social Welfare } \\
\text { Education }\end{array}$ & 790 & Sports and Recreation \\
\hline 380 & $\begin{array}{l}\text { Public Services and } \\
\text { Utilties }\end{array}$ & $\begin{array}{l}800 \\
810\end{array}$ & $\begin{array}{l}\text { Literature } \\
\text { American Literature }\end{array}$ \\
\hline 390 & Customs and Folklore & $\begin{array}{l}820 \\
830\end{array}$ & $\begin{array}{l}\text { English Literature } \\
\text { Germanic Literature }\end{array}$ \\
\hline 400 & Language & $\begin{array}{l}840 \\
850\end{array}$ & $\begin{array}{l}\text { French Literature } \\
\text { Italian and Roman }\end{array}$ \\
\hline 500 & Mathematics and Science & & Literature \\
\hline 510 & Mathematics & 860 & Spanish Literature \\
\hline $\begin{array}{l}520 \\
530\end{array}$ & $\begin{array}{l}\text { Astronomy } \\
\text { Physics }\end{array}$ & 870 & Latin and Other Italic \\
\hline 540 & $\begin{array}{l}\text { Physics } \\
\text { Chemistry }\end{array}$ & 880 & $\begin{array}{c}\text { Literatures } \\
\text { Classic and Modern }\end{array}$ \\
\hline 550 & Earth Science & 000 & Greek \\
\hline 560 & Paleontology & 890 & Other Literatures \\
\hline 570 & Biology & & \\
\hline 580 & Botany & 900 & Geography and History \\
\hline 59 & Zoology & $\begin{array}{l}910 \\
920\end{array}$ & $\begin{array}{l}\text { Travel } \\
\text { Biography }\end{array}$ \\
\hline 600 & Technology & 930 & Ancient History \\
\hline 61 & Medicine & 940 & European History \\
\hline 620 & Engineering & 950 & Asian History \\
\hline 63 & Agriculture & 960 & African History \\
\hline 64 & Home Economics & 970 & American History \\
\hline 65 & Management & 980 & South American History \\
\hline & Chemical Technology & 990 & Other Parts of World \\
\hline
\end{tabular}


APPENDEX 2

COLLECTION PROFILES OF THE 500 AND 700 THROUGH 900 SUBJECT CATEGORIES 


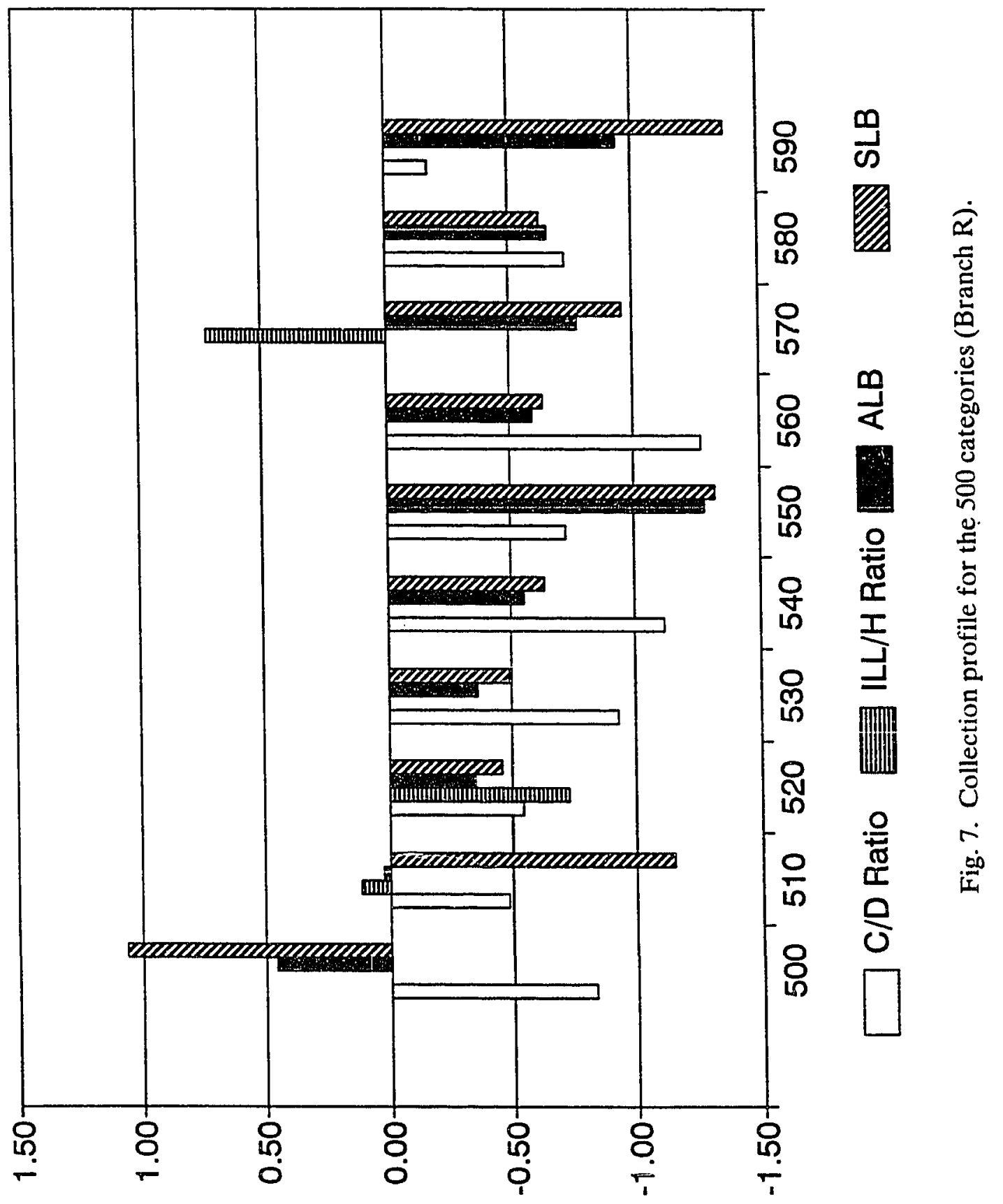




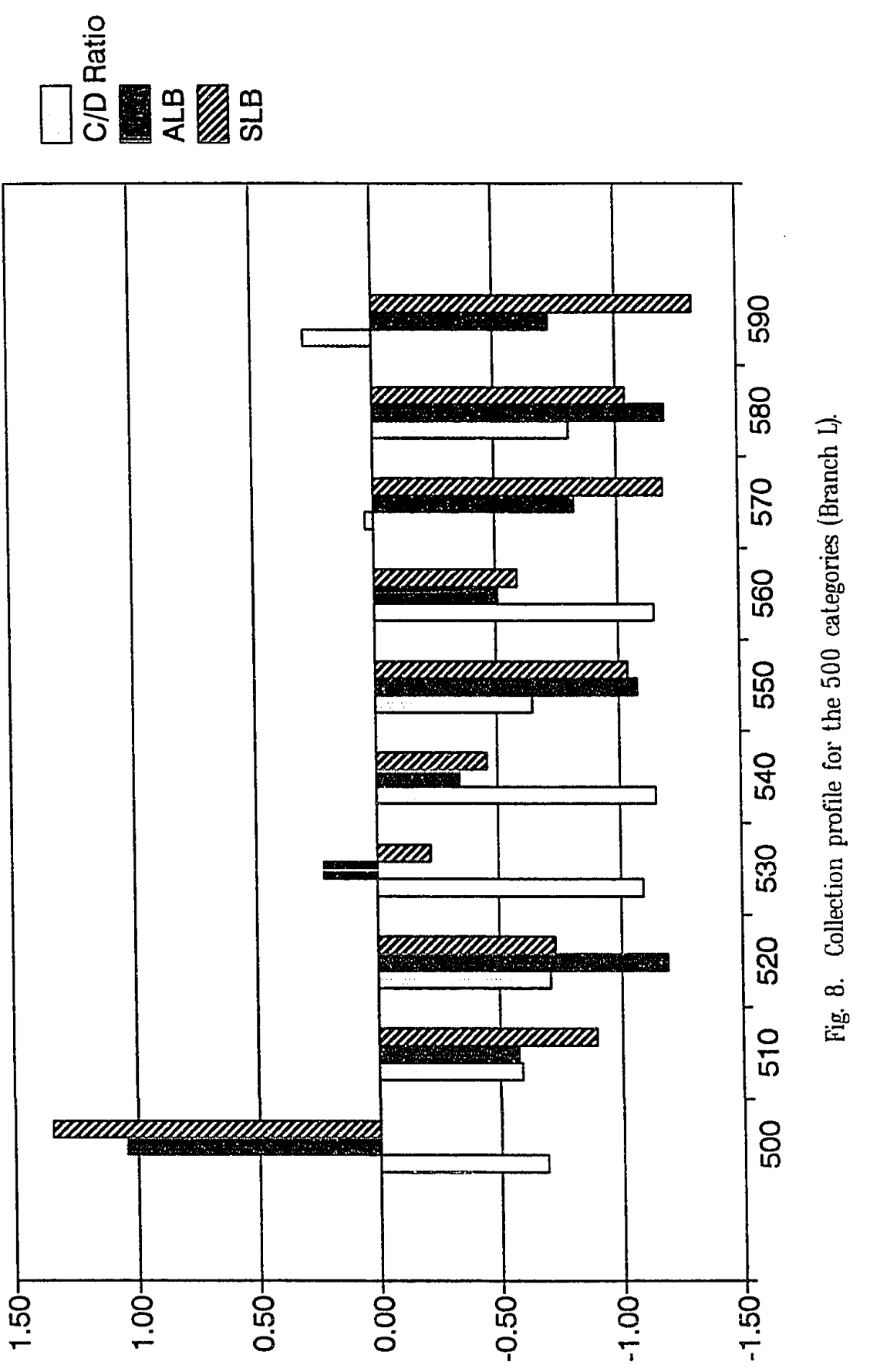




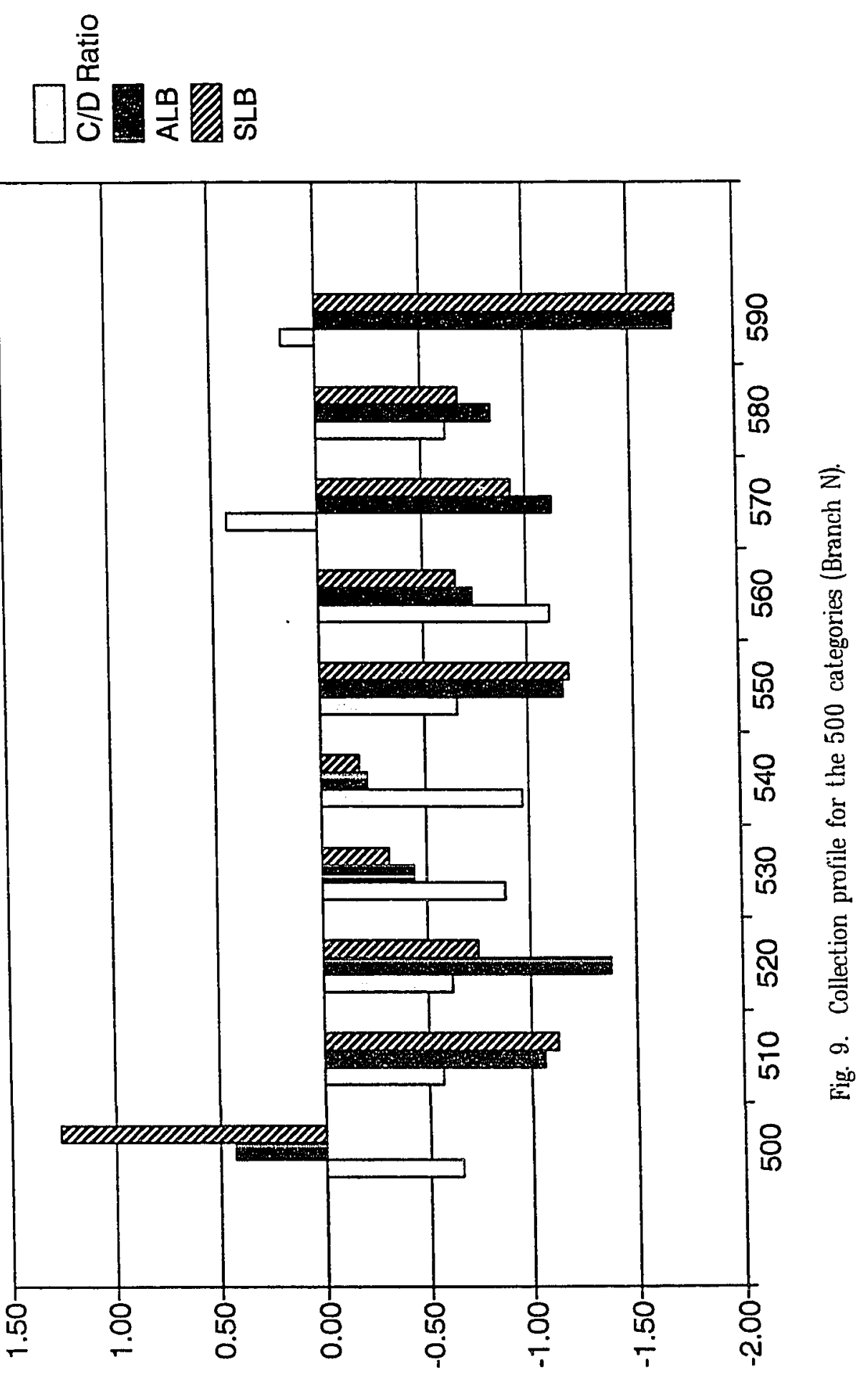




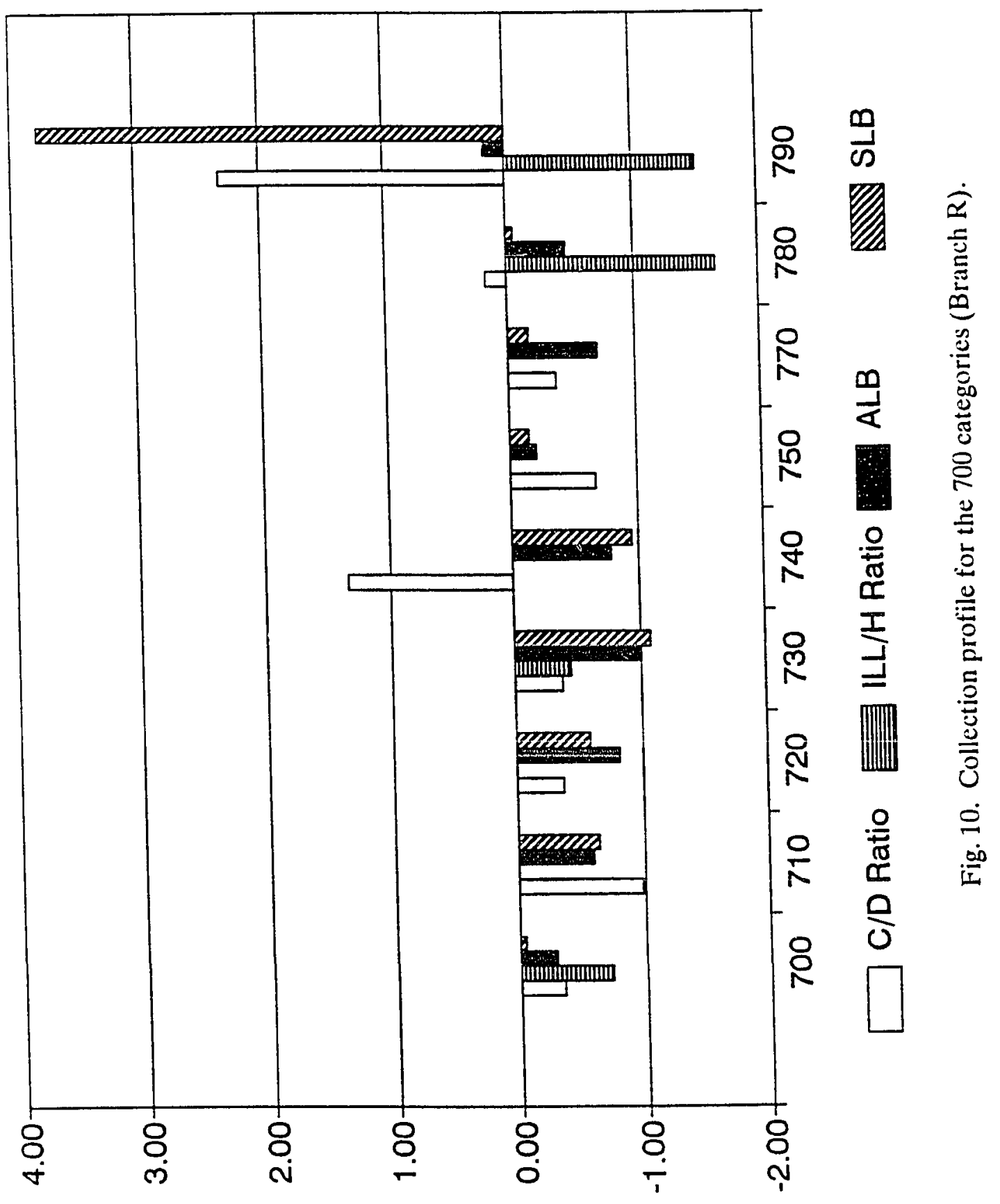




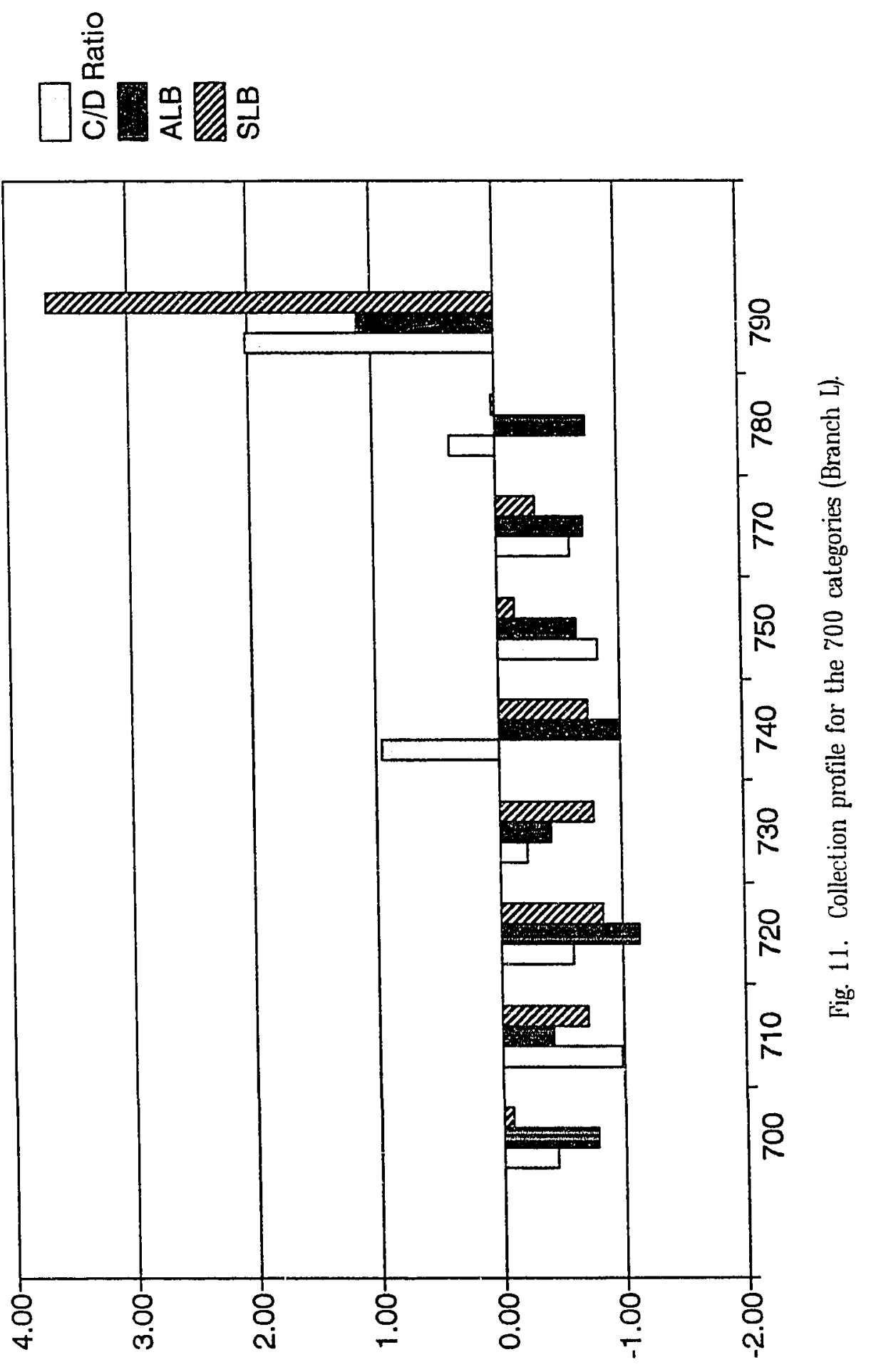




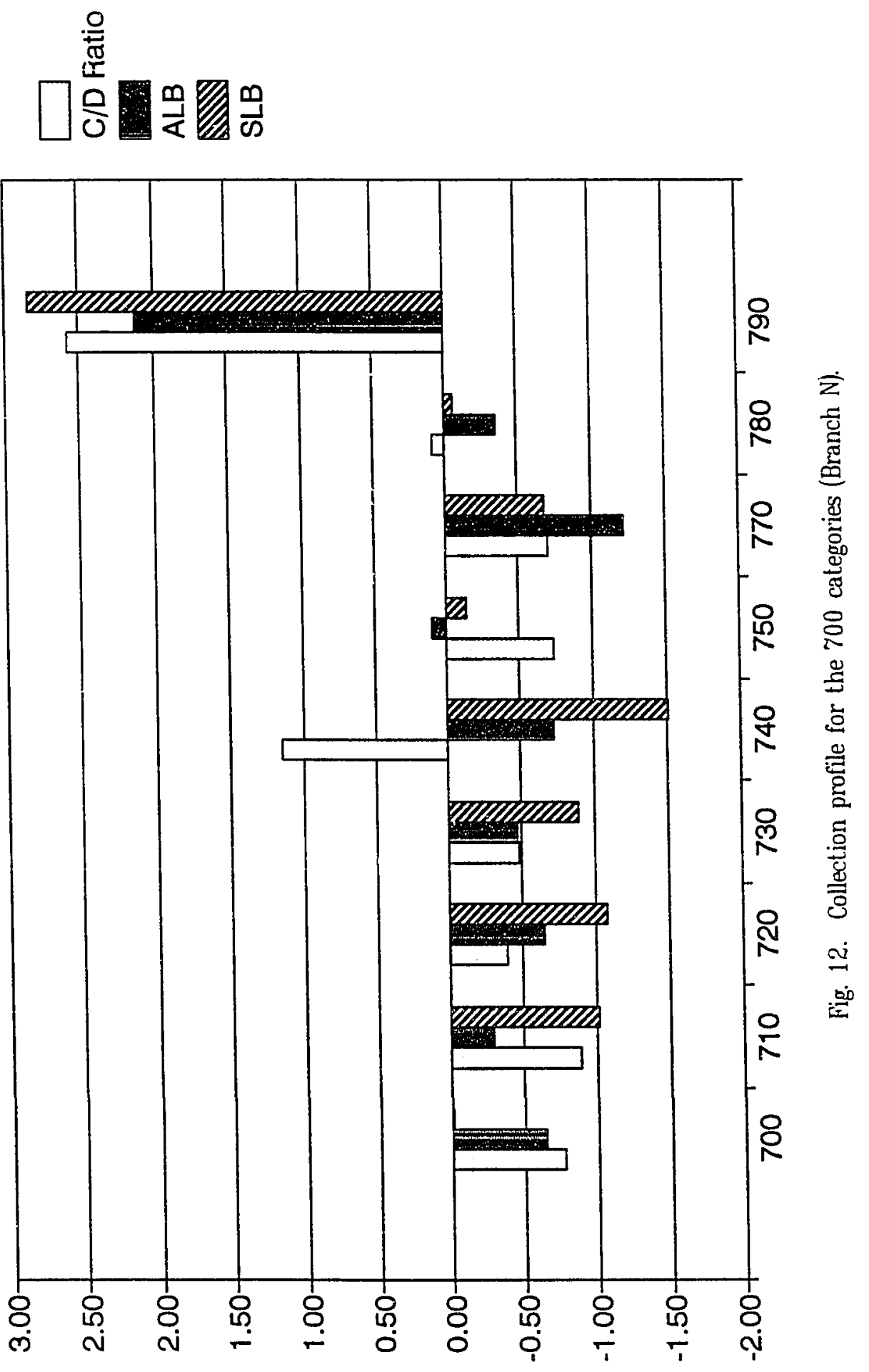




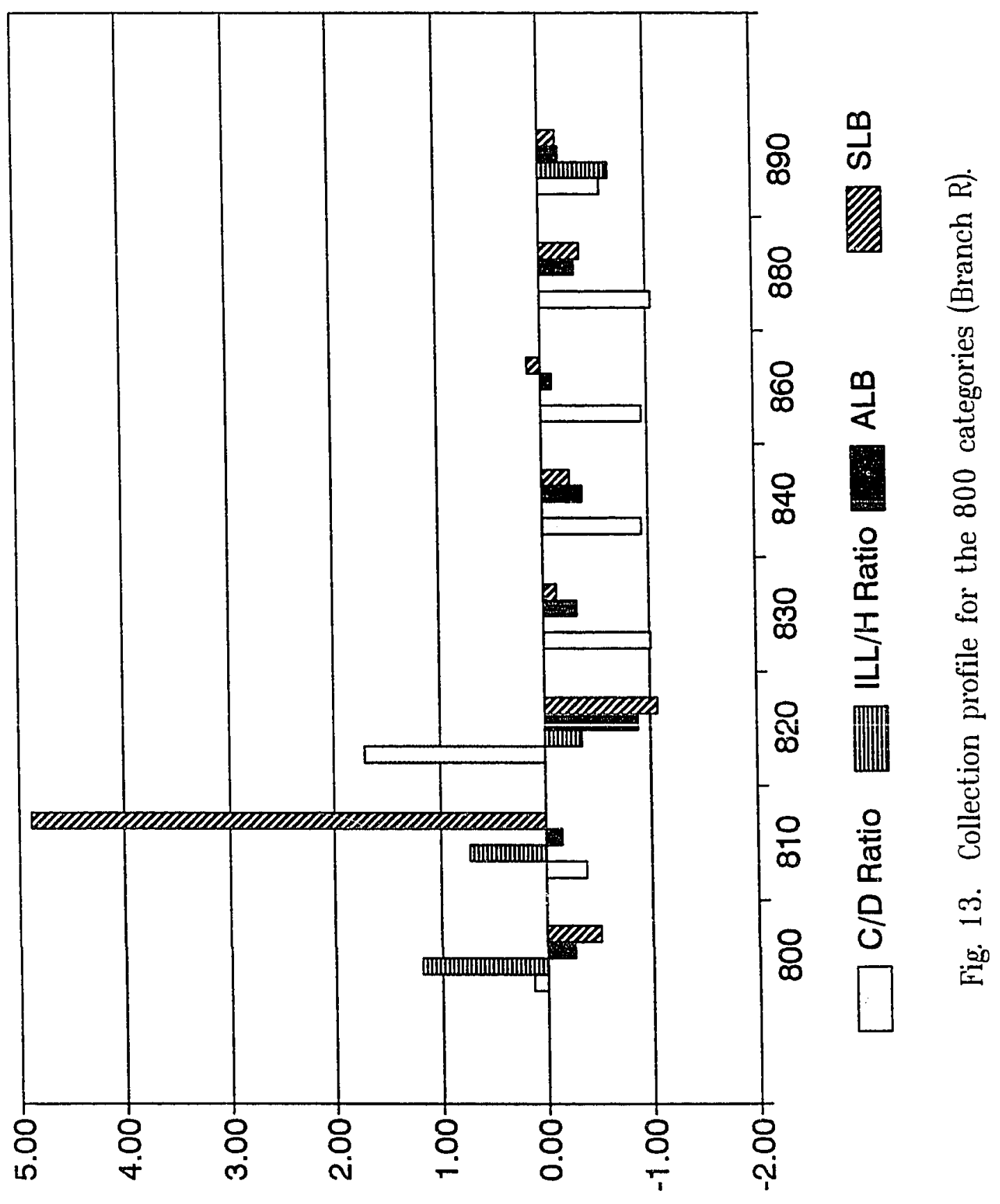




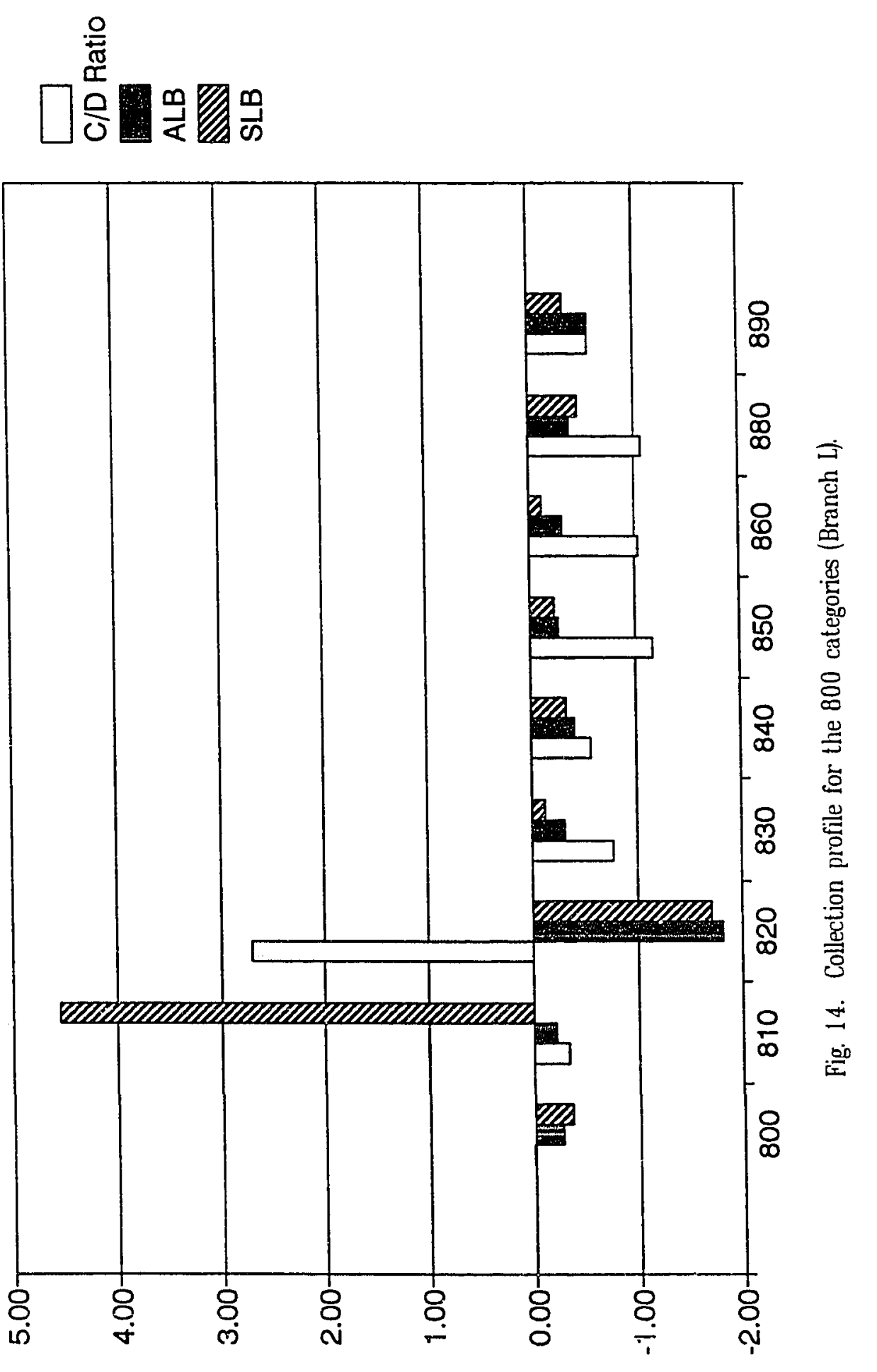




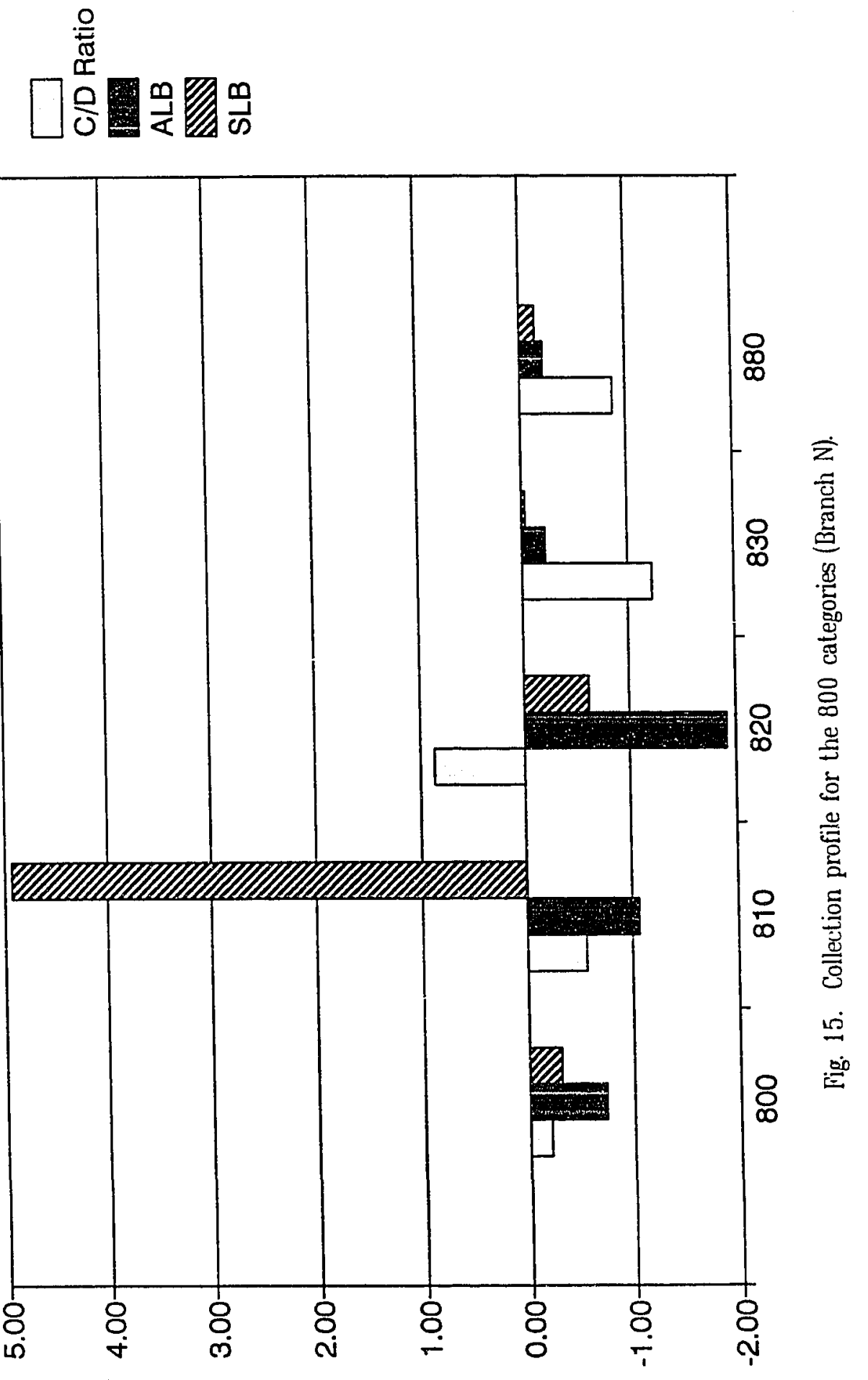




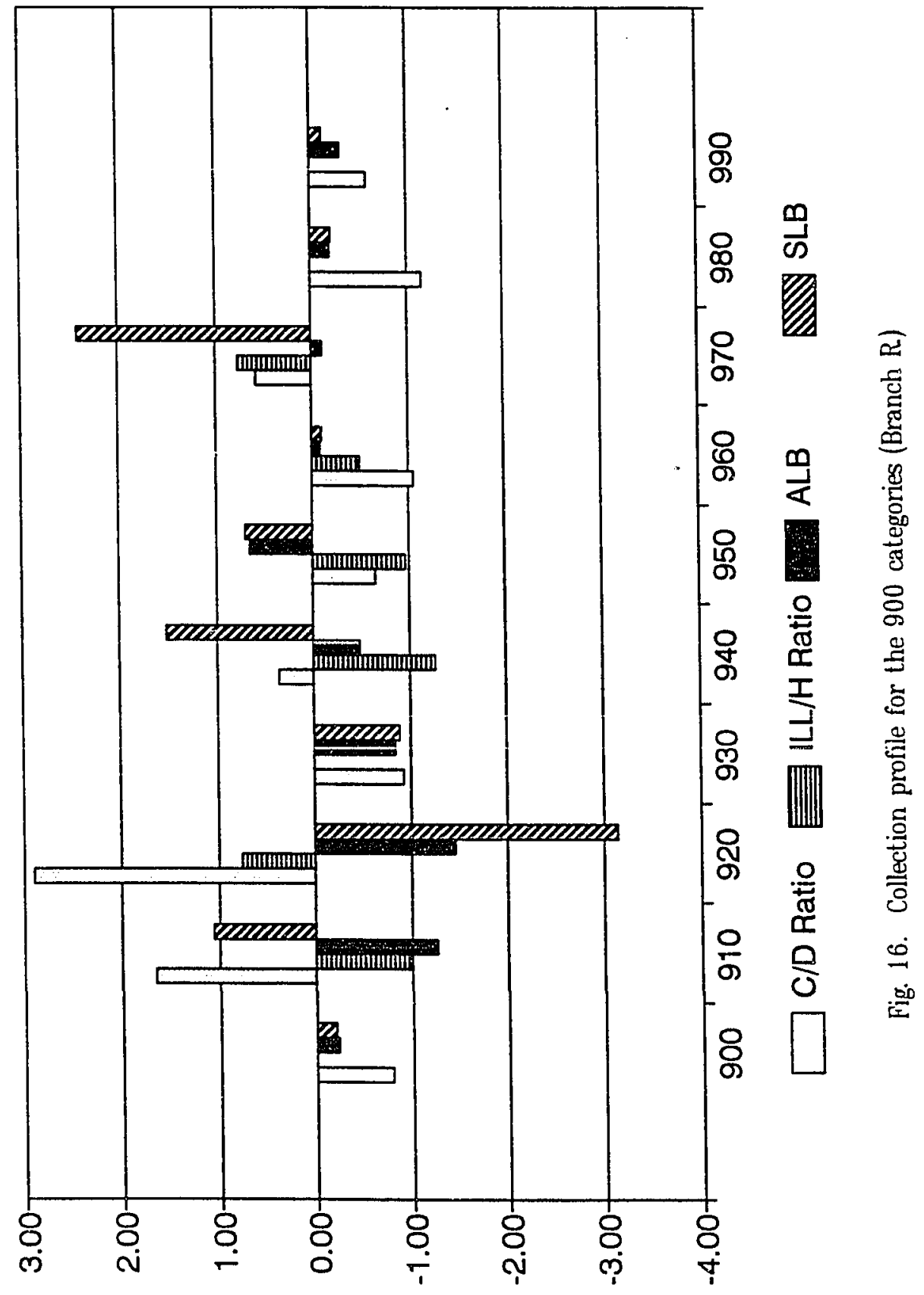




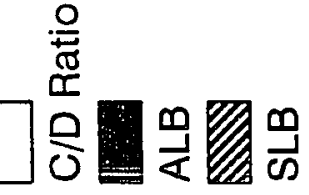

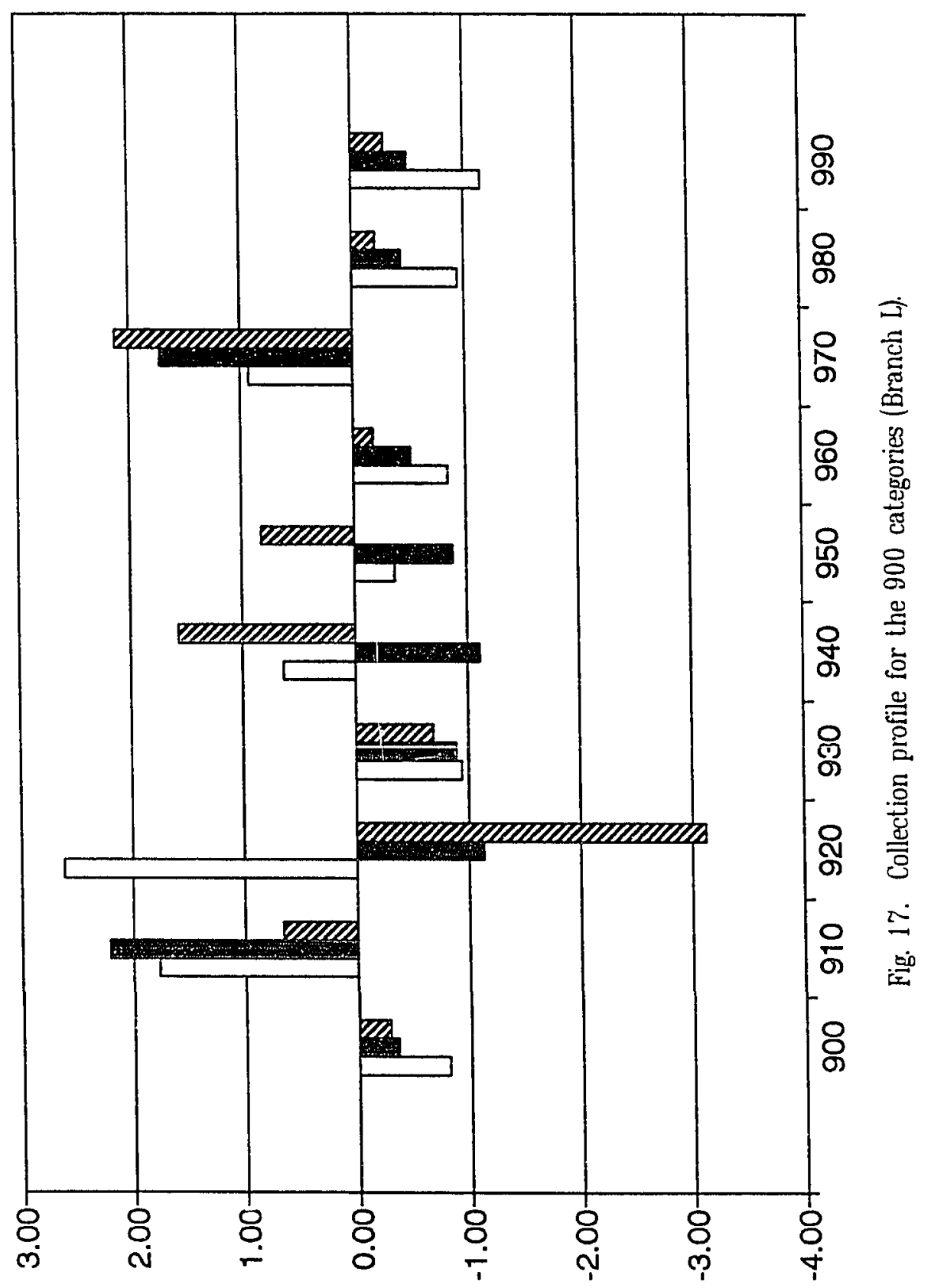




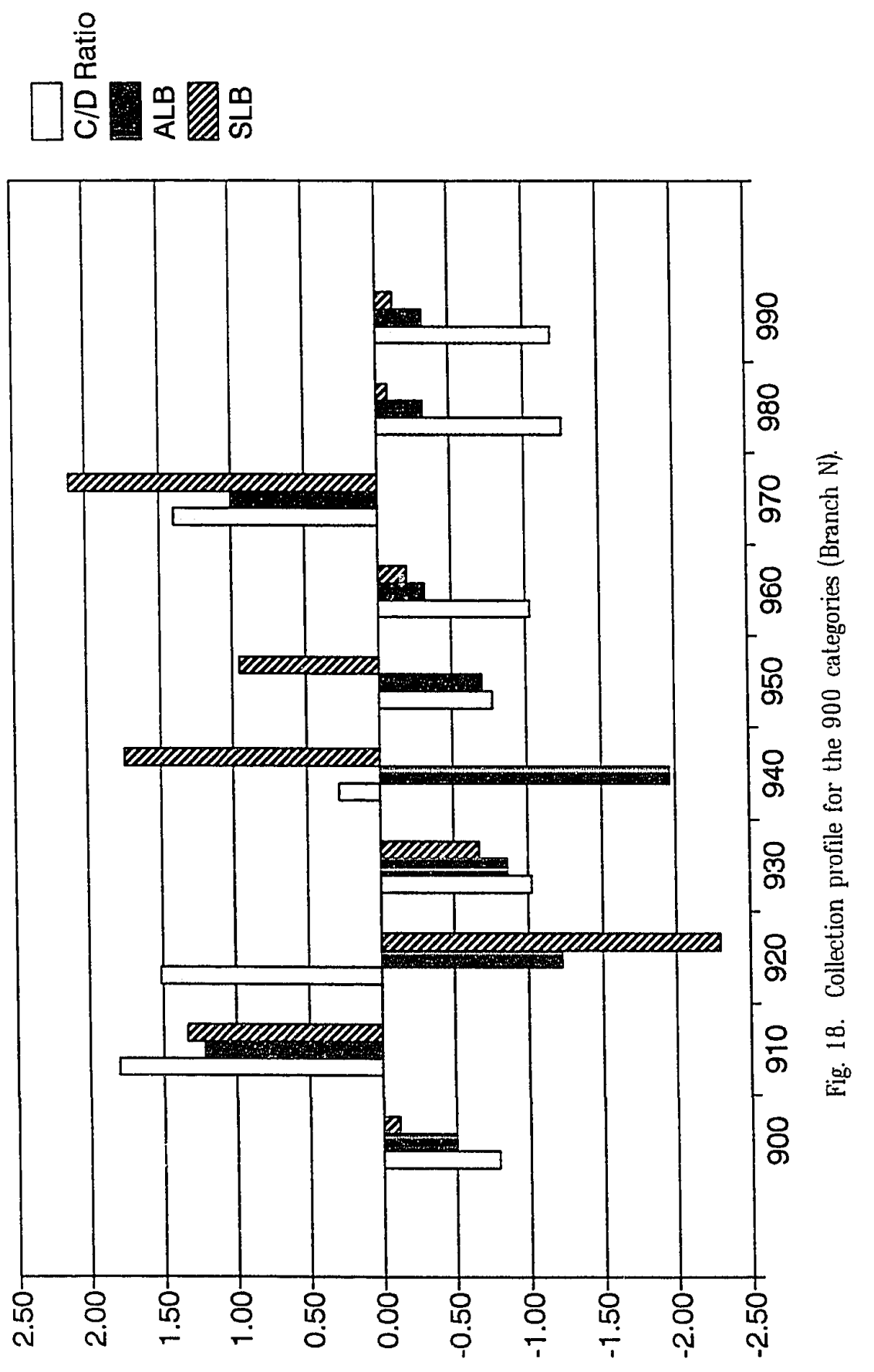




\section{BIBLIOGRAPHY}

Aguilar, William. "The Application of Relative Use and Interlibrary Demand in Collection Development." Collection Management 8 (Spring 1986): 15-23.

Anderson, Charles. "Using Technology: Spreadsheet Programs and Collection Development." Wilson Library Bulletin 65 (September 1990): 90-94.

Baker, Robert K. "Using a Turnkey Automated System to Support Collection Assessment." College and Research Libraries 51 (July 1990): 360-366.

Baker, Sharon L. , "Public Libraries." In Collection Management: A New Treatise, ed. Charles B. Osborn and Ross Atkinson. Greenwich, CT: JAI Press, 1991.

Bommer, M.R.W., The Development of a Management System for Effective Decision Making and Planning in a University Library. Philadelphia: University of Pennsylvania, Wharton School of Finance and Commerce, 1973.

Bonn, George S. "Evaluation of the Collection." Library Trends 22 (January 1974): 265-304.

Buckland, M. K. et al, "Methodological problems in Assessing the Overlap Between Bibliographic Files and Library Holdings." Information Processing and Management 11 (1975): 89-105.

D'Elia, George. "Materials Availability Fill Rates: Additional Data Addressing the Question of the Usefulness of the Measures." Public Libraries 27 (January/February 1988): 15-23.

Domas, R.E. Correlating the Classes of Books Taken Out of and Books Used Within an Open-Stack Library. San Antonio: San Antonio College Library, 1978.

Dowlin, K. \& Magrath, L. "Beyond the Numbers--a Decision Support System." In Library Automation as a Source of Management Information, ed. F.W. Lancaster. Champaign, Ill.: University of Illinois, 1983.

Evans, Glyn \& Beilby, Albert. "A Library Management Information System in a Multi-Campus Environment." In Library Automation as a Source of Management Information, ed. F.W. Lancaster. Champaign, Ill.: University of Illinois, 1983. 
Fussler, H.H. and Simon, J.L. Patterns in the Use of Books in Large Research Libraries. Chicago: University of Chicago Press, 1969.

Guide to the Evaluation of Library Collections. Chicago: American Library Association, 1989.

Hamilton, Patricia \& Weech,Terry. "The Development and Testing of an Instrument to Measure Attitudes toward the Quality vs. Demand Debate in Collection Management." Collection Management 10 (1988): 27-42.

Hardesty, L. "Use of Library Materials at a Small Liberal Arts College." Library Research 3 ((1982): 265.

Jain, A.K. A Sampled Data Siudy of Book Usage in the Purdue University Libraries Lafayette, IN: Purdue University, 1965.

Kohl, David F. "Collection Development--An Overview of the Research." Collection Management 10 (1988): 1 -13.

Hindle, A. and Buckland, M.K. "In-Library Book Usage in Relation to Circulation." Collection Management 2 (1978): 265-277.

Lancaster, F.W. If You Want to Evaluate Your Library. Champaign, Ill.: University of Illinois, 1988.

Loertscher, David V. "Collection Mapping: An Evaluation Strategy for Collection Development." Drexel Library Quarterly 21 (Spring 1985): 9-21.

Magrill, Rose Mary \& Corbin, John. Acquisitions Management and Collection Development in Libaries. 2d ed. Chicago: American Library Association, 1989.

McClellan, A.W. "Systematic Stock Control in Public Libraries." Ch. 8 in The Reader, the Library and the Book. London: Clive Bingley, 1973.

McClure, Charles R. , "Increasing the Usefulness of Research for Library Managers: Propositions, Issues, and Strategies." Library Trends 38 (Fall 1989): $280-294$.

McGrath, W. E. "Correlating the Subjects of Books Taken Out of and Books Used Within an Open-Stack Library." College and Research Libraries 32 (1971): 280-285.

Merritt, LeRoy C. Book Selection and Intellectual Freedom. New York: H.W. Wilson Co., 1970.

Mostyn, Gregory. "The use of Supply-Demand Equality in Evaluating Collection Adequacy." Califomia Librarian 35 (April 1974): 16-23. 
Olsgaard,John N. "Characteristics of Managerial Resistance to Library Management Information Systems." In Librany Automation as a Source of Management Information. Champaign, Ill.: University of Illinois, 1983.

Robinson, Charles. "The Public Library Vanishes." Library Jourial 117 (March 15, 1992): 51-54.

Van House, Nancy et al. Output Measures for Public Libraries. 2ed. Chicago: American Library Association, 1987. 